\title{
A Retrospective Evaluation of the Storm Surge Produced by Hurricane Gustav (2008): Forecast and Hindcast Results
}

\author{
CRISTINA FORBES* AND RICHARD A. LUETTICH JR. \\ Institute of Marine Sciences, University of North Carolina at Chapel Hill, Morehead City, North Carolina
}

\author{
CRAig A. MATTOCKS
}

Morehead City Field Site, Institute for the Environment, University of North Carolina, Morehead City, North Carolina

\author{
JOANNES J. WESTERINK
}

Department of Civil Engineering and Geological Sciences, University of Notre Dame, South Bend, Indiana

(Manuscript received 2 March 2010, in final form 23 June 2010)

\begin{abstract}
The evolution and convergence of modeled storm surge were examined using a high-resolution implementation of the Advanced Circulation Coastal Ocean and Storm Surge (ADCIRC) model for Hurricane Gustav (2008). The storm surge forecasts were forced using an asymmetric gradient wind model (AWM), directly coupled to ADCIRC at every time step and at every grid node. A total of 20 forecast advisories and best-track data from the National Hurricane Center (NHC) were used as input parameters into the wind model. Differences in maximum surge elevations were evaluated for ensembles comprised of the final 20, 15, 10 , and 5 forecast advisories plus the best track. For this particular storm, the final 10-12 forecast advisories, encompassing the last 2.5-3 days of the storm's lifetime, give a reasonable estimate of the final storm surge and inundation. The results provide a detailed perspective of the variability in the storm surge due to variability in the meteorological forecast and how this changes as the storm approaches landfall. This finding is closely tied to the consistency and accuracy of the NHC storm track forecasts and the predicted landfall location and, therefore, cannot be generalized to all storms in all locations. Nevertheless, this first attempt to translate variability in forecast meteorology into storm surge variability provides useful insights for guiding the potential use of storm surge models for forecast purposes. Model skill was also evaluated for Hurricane Gustav by comparing observed water levels with hindcast modeled water levels forced by river flow, tides, and several sources of wind data. The AWM (which ingested best-track information from NHC) generated winds that were slightly higher than those from NOAA's Hurricane Research Division (HRD) H*Wind analyses and substantially greater than the North American Mesoscale (NAM) model. Surge obtained using the AWM more closely matched the observed water levels than that computed using $\mathrm{H}^{*} \mathrm{Wind}$; however, this may be due to the neglect of the contribution of wave setup to the surge, especially in exposed areas. Several geographically distinct storm surge response regimes, some characterized by multisurge pulses, were identified and described.
\end{abstract}

\section{Introduction}

In the years since Hurricane Katrina (2005), considerable effort has been invested into improving our ability to model coastal storm surge. The resulting advancements

\footnotetext{
* Current affiliation: Storm Surge Unit, National Hurricane Center, Miami, Florida.

Corresponding author address: Cristina Forbes, Storm Surge Unit, National Hurricane Center, 11691 SW 17th St., Miami, FL 33165. E-mail: cristina.forbes@noaa.gov
}

have included the development of more accurate and realistic meteorological forcing, the addition of more complete physics such as the contribution of short waves to surge, and the development of model grids with very high resolution and detail to capture bathymetric and topographic features in areas near and on shore (Resio and Westerink 2008). One cost of these model enhancements has been a substantial escalation in the required computer time (Tanaka et al. 2010). Consequently, their uses have been limited mostly to forensic hindcast studies (Ebersole et al. 2007), design studies (USACE 2009), and Federal Emergency Management Agency (FEMA) 
National Flood Insurance Program studies (FEMA 2008), all of which allow flexible limits on model execution time. On the other hand, real-time forecasting applications have much more strict model execution time constraints and, therefore, have tended to favor simpler model implementations (e.g., coarse grid resolution) that are able to produce output more rapidly.

With the increased availability of high-performance computing systems containing many thousands of compute cores, (e.g., National Science Foundation TeraGrid supercomputing clusters), it is becoming possible to expeditiously run 3-5-day storm surge forecasts using a more computationally intensive modeling system. This raises the question of whether the additional computational effort is worthwhile, given the expected error in storm surge due to inaccuracies in the tropical cyclone forecast meteorology. The answer is not obvious because there have been no previous studies of how forecast meteorology error translates into storm surge error.

The evolution and convergence of modeled storm surge were examined using a high-resolution implementation of the Advanced Circulation Coastal Ocean and Storm Surge (ADCIRC) model. This is accomplished using the final 20 meteorological forecasts (covering the final 5 days) during which Hurricane Gustav (2008) made landfall west of the Mississippi River delta. The results provide a detailed perspective, for this specific storm, of the variability in the storm surge due to variability in the meteorological forecast and how this changes as the storm approaches landfall. The conclusions of this analysis depend on both the quality of the meteorological forecasts and on the landfall location and, therefore, cannot be generalized to all storms in all locations. Nevertheless, this first attempt to translate variability in forecast meteorology into storm surge variability provides useful insights for guiding the potential use of storm surge models for forecast purposes.

The 2008 Atlantic hurricane season was highly destructive, with many casualties and widespread devastation in the Caribbean, Central America, and the United States. For the first time in recorded history, six consecutive tropical cyclones (Dolly, Edouard, Fay, Gustav, Hanna, and Ike) made landfall along the U.S. coastline, and three major hurricanes (Gustav, Ike, and Paloma) hit Cuba. Hanna, Ike, and Gustav, the deadliest hurricanes of the season, caused several hundred casualties in the Caribbean (WMO 2008).

The state of Louisiana, bordered on the south by the warm Gulf of Mexico, is particularly prone to hurricane impact. More than 53 hurricanes (20 of them major, i.e., of category 3 strength or higher) have struck Louisiana since 1851 (Blake et al. 2007). The Mississippi River flows through the state, forming a delta that extends close to the continental shelf break. Tidal freshwater wetlands are formed at outlets of coastal rivers with low topographic relief at or near sea level (Doyle et al. 2007). However, dams, levees, and artificial channeling have reduced the amount of sediment transported down the Mississippi River, over its banks and into the delta, decreasing the rate of land accretion and increasing the net subsidence. Channelization, subsidence, and sea level rise have caused intrusions of saltwater, resulting in the widespread loss of wetlands and accelerated erosion. Thus, the southern part of the state is characterized by disappearing wetlands, swamps, cypress forest, freshwater marsh, and low-lying coastal plains that are highly susceptible to flooding from hurricane storm surge.

Hurricane Gustav was the seventh tropical storm and the third hurricane of the 2008 season. It began as a tropical wave in the Lesser Antilles, then rapidly intensified from a tropical depression to a hurricane in $12 \mathrm{~h}$ (Beven and Kimberlain 2009). The lowest central pressure reported by hurricane reconnaissance aircraft was $941 \mathrm{mb}$ at 2154 UTC on 30 August. It struck Cuba as a category 4 storm. Hurricane Gustav reached its peak intensity, with 1-min maximum sustained winds of $69 \mathrm{~m} \mathrm{~s}^{-1}$ at $10 \mathrm{~m}$ reported as it made landfall in western Cuba. It was the most intense storm to hit Cuba in five decades. A peak wind gust of $95 \mathrm{~m} \mathrm{~s}^{-1}$ was recorded in Paso Real San Diego, the highest recorded wind speeds in Cuba's history (WMO 2008). Hurricane Gustav decreased in strength in the Gulf of Mexico due to increased wind shear and intrusions of dry air. It grew in size as it crossed the Gulf, making landfall at 1500 UTC [1000 central daylight time (CDT)] on 1 September 2008 near Cocodrie, Louisiana. At landfall, Hurricane Gustav was a category 2 storm on the SaffirSimpson scale, with 1-min maximum sustained winds of $46 \mathrm{~m} \mathrm{~s}^{-1}$. Hurricane-force winds extended out $130 \mathrm{~km}$ and tropical-storm-force winds extended $370 \mathrm{~km}$ from the center in the northeast quadrant (Beven and Kimberlain 2009). The hurricane weakened to a tropical storm and its forward motion slowed as it crossed southern and western Louisiana later on 1 September. Its status was downgraded to a tropical depression on 2 September over northwestern Louisiana.

The hurricane caused widespread storm surge along the northern Gulf coast, with above-normal water levels reported from the Florida panhandle to the upper Texas coast, including Lake Pontchartrain. Surges of 3.6-4 m occurred along the Louisiana coast in the Mississippi River Delta southeast of New Orleans, Louisiana, with surges of 2.7-3 $\mathrm{m}$ in other portions of southeastern Louisiana. The storm surge minimally overtopped levees and floodwalls in parts of the New Orleans metropolitan area, but did not cause widespread inundation 
of the city and its suburbs (Beven and Kimberlain 2009), as occurred during Katrina.

Gustav triggered one of the largest evacuations in U.S. history (more than 2 million people), as traffic streamed northbound along two contraflow (traffic lane reversal to aid in evacuation) routes out of Louisiana and into Mississippi. This included a mandatory evacuation of New Orleans, ordered the morning of 31 August 2008. In addition to evacuation, numerous storm-instigated activities occurred throughout the predicted storm impact zone, including closing flood control gates, positioning and deploying first responders and maintenance/ repair crews, and developing initial damage assessments for federal aid requests. The success of these activities during Gustav and future tropical cyclones depends on the forecast accuracy of the storm and the ability to forecast the accompanying storm surge. While there have been extensive evaluations of hurricane forecast accuracy (Franklin 2008; Rogers 2009), there have been few systematic evaluations of hurricane storm surge forecast accuracy, particularly using recently developed highresolution storm surge models.

In this paper, we analyze the variability and convergence of numerical model storm surge forecasts using a high-resolution implementation of the ADCIRC model forced by an asymmetric gradient wind model (AWM) that ingests track information issued from the final 20 forecast advisories provided by the National Hurricane Center (NHC) for Hurricane Gustav (2008). We also compare hindcast water levels forced by 1) the AWM using NHC best-track data, 2) National Oceanic and Atmospheric Administration (NOAA) HRD H*Wind analyses, and 3) gridded North American Mesoscale (NAM) model wind fields to evaluate the storm surge model skill. The storm surge and wind model are described in section 2. Forecast simulations, tracks, and storm surge predictions are described in sections 3 and 4 . Hindcast water levels and wind results are reported in section 5. Comparisons of simulation results with observations are described in section 6.

\section{Storm surge and wind models}

\section{a. ADCIRC model}

The Hurricane Gustav forecast and hindcast simulations were conducted with the ADCIRC model version 47_31.1 (Luettich et al. 1992; Luettich and Westerink 2006) using the high-resolution southern Louisiana grid (SL15v3r9a). ADCIRC has been used extensively to compute storm surge and inundation (Blain et al. 1994; Luettich et al. 1996; Blain and McManus 1998; Blain et al. 1998; Lynch et al. 2004; Graber et al. 2006;

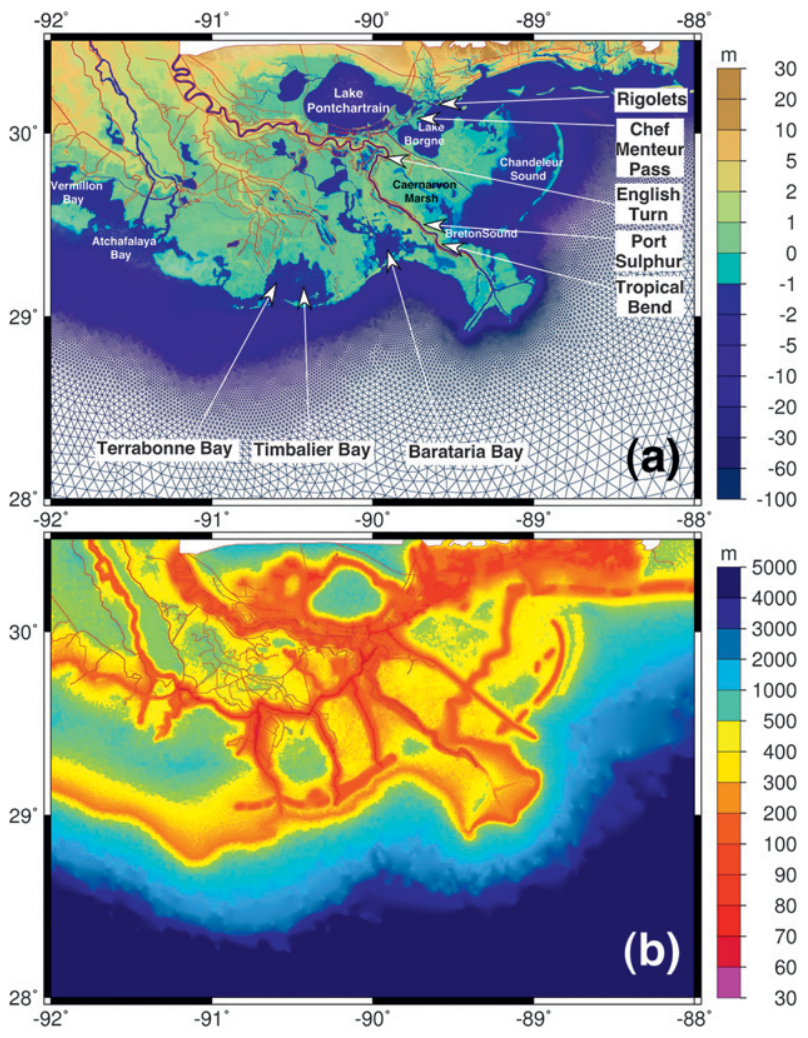

FIG. 1. (a) High-resolution grid and bathymetry and topography over southern LA from the ADCIRC SL15v3r9a grid. (b) Grid size (m) of the ADCIRC SL15v3r9a grid over southern LA.

Dietsche et al. 2007; Mattocks and Forbes 2008; Fleming et al. 2008; Westerink et al. 2008; Dietrich et al. 2010; Bunya et al. 2010). SL15 grids have been employed in several recent storm surge studies in southern Louisiana (FEMA 2008; USACE 2009). The unstructured, triangular grid consists of more than 2 million computational nodes; includes all waters in the western Atlantic, Caribbean and Gulf of Mexico that lie to the west of the $60^{\circ} \mathrm{W}$ meridian; has its highest resolution (less than $30 \mathrm{~m}$ ) in southern Louisiana (Figs. 1a and 1b); and is referenced to the North American Vertical Datum of 1988 (NAVD88).

The ADCIRC model runs in a vertical reference frame that is based on mean sea level (MSL) plus a seasonal steric height correction. The relationship between MSL and NAVD88 was determined at 11 NOAA tide gauge stations using relationships provided by the National Geodetic Survey (NGS) and the NOAA Center for Operational and Oceanographic Products and Services (CO-OPS) plus a correction to account for recent relative sea level rise. Relationships at the NOAA tide stations are referenced to the National Tidal Datum Epoch (1983-2001; see Table 1, Fig. 2a). They were averaged across the region to yield a single representative 
TABLE 1. Difference between the CO-OPS MSL and NGS NAVD88 elevations $(\mathrm{m})$ in locations where the tidal information and orthometric elevations of a specific survey control mark are available. Tidal data MSL and mean lower low water (MLLW) referenced on 1983-2001 epoch.

\begin{tabular}{|c|c|c|c|c|c|c|c|c|c|}
\hline Station & Lat $\left(^{\circ}\right)$ & Lon $\left(^{\circ}\right)$ & ID & Bench-mark & Station ID & $\begin{array}{c}\text { MSL } \\
\text { relative } \\
\text { to MLLW }\end{array}$ & $\begin{array}{l}\text { NAVD88 } \\
\text { relative } \\
\text { to MLLW }\end{array}$ & $\begin{array}{c}\text { MSL - } \\
\text { NAVD88 }\end{array}$ & $\begin{array}{l}\text { Avg MSL - } \\
\text { NAVD88 } \\
\text { by station }\end{array}$ \\
\hline Leeville, LA & $29^{\circ} 14.9^{\prime} \mathrm{N}$ & $90^{\circ} 12.7^{\prime} \mathrm{W}$ & AU1255 & JESSE & 8762084 & 0.143 & -0.151 & 0.294 & 0.294 \\
\hline $\begin{array}{l}\text { Cheniere } \\
\text { Caminada, LA }\end{array}$ & $29^{\circ} 12.6^{\prime} \mathrm{N}$ & $90^{\circ} 2.4^{\prime} \mathrm{W}$ & AU1289 & P 221 & 8761826 & 0.150 & -0.180 & 0.330 & 0.330 \\
\hline New Canal & $30^{\circ} 1.6^{\prime} \mathrm{N}$ & $90^{\circ} 6.8^{\prime} \mathrm{W}$ & BJ3686 & X 374 & 8761927 & 0.075 & -0.161 & 0.236 & 0.234 \\
\hline Station, LA & $\begin{array}{l}30^{\circ} 1.6^{\prime} \mathrm{N} \\
30^{\circ} 1.6^{\prime} \mathrm{N}\end{array}$ & $\begin{array}{l}90^{\circ} 6.8^{\prime} \mathrm{W} \\
90^{\circ} 6.8^{\prime} \mathrm{W}\end{array}$ & $\begin{array}{l}\text { BJ1342 } \\
\text { BJ1344 }\end{array}$ & $\begin{array}{l}\text { ALCO } \\
\text { ALCO RM }\end{array}$ & $\begin{array}{l}8761927 \\
8761927\end{array}$ & $\begin{array}{l}0.075 \\
0.075\end{array}$ & $\begin{array}{l}-0.159 \\
-0.157\end{array}$ & $\begin{array}{l}0.234 \\
0.232\end{array}$ & \\
\hline Pass Christian & $30^{\circ} 18.6^{\prime} \mathrm{N}$ & $89^{\circ} 14.7^{\prime} \mathrm{W}$ & BH0916 & Y 214 & 8746819 & 0.267 & 0.122 & 0.145 & 0.151 \\
\hline Yacht, MS & $30^{\circ} 18.6^{\prime} \mathrm{N}$ & $89^{\circ} 14.7^{\prime} \mathrm{W}$ & ВН0917 & V 190 & 8746819 & 0.267 & 0.111 & 0.156 & \\
\hline Biloxi, MS & $\begin{array}{l}30^{\circ} 23.4^{\prime} \mathrm{N} \\
30^{\circ} 23.4^{\prime} \mathrm{N}\end{array}$ & $\begin{array}{l}88^{\circ} 51.4^{\prime} \mathrm{W} \\
88^{\circ} 51.4^{\prime} \mathrm{W}\end{array}$ & $\begin{array}{l}\text { BH0390 } \\
\text { BH0392 }\end{array}$ & $\begin{array}{l}\text { TIDAL } 1 \\
\text { TIDAL } 3\end{array}$ & $\begin{array}{l}8743735 \\
8743735\end{array}$ & $\begin{array}{l}0.270 \\
0.270\end{array}$ & $\begin{array}{l}0.115 \\
0.114\end{array}$ & $\begin{array}{l}0.155 \\
0.156\end{array}$ & 0.156 \\
\hline Bay Waveland & $30^{\circ} 19.5^{\prime} \mathrm{N}$ & $89^{\circ} 19.5^{\prime} \mathrm{W}$ & ВH0934 & WEST & 8747437 & 0.265 & 0.099 & 0.166 & 0.167 \\
\hline Yacht, MS & $\begin{array}{l}30^{\circ} 19.5^{\prime} \mathrm{N} \\
30^{\circ} 19.5^{\prime} \mathrm{N} \\
30^{\circ} 19.5^{\prime} \mathrm{N}\end{array}$ & $\begin{array}{l}89^{\circ} 19.5^{\prime} \mathrm{W} \\
89^{\circ} 19.5^{\prime} \mathrm{W} \\
89^{\circ} 19.5^{\prime} \mathrm{W}\end{array}$ & $\begin{array}{l}\text { BH0935 } \\
\text { BH0936 } \\
\text { BH0937 }\end{array}$ & $\begin{array}{l}\text { Z } 214 \\
\text { TIDAL } 2 \\
\text { TIDAL } 1\end{array}$ & $\begin{array}{l}8747437 \\
8747437 \\
8747437\end{array}$ & $\begin{array}{l}0.265 \\
0.265 \\
0.265\end{array}$ & $\begin{array}{l}0.100 \\
0.098 \\
0.096\end{array}$ & $\begin{array}{l}0.165 \\
0.167 \\
0.169\end{array}$ & \\
\hline Greens Ditch, LA & $\begin{array}{l}30^{\circ} 6.7^{\prime} \mathrm{N} \\
30^{\circ} 6.7^{\prime} \mathrm{N}\end{array}$ & $\begin{array}{l}89^{\circ} 45.6^{\prime} \mathrm{W} \\
89^{\circ} 45.6^{\prime} \mathrm{W}\end{array}$ & $\begin{array}{l}\text { BH1145 } \\
\text { BH1147 }\end{array}$ & $\begin{array}{l}\text { E } 193 \\
\text { E } 92\end{array}$ & $\begin{array}{l}8761426 \\
8761426\end{array}$ & $\begin{array}{l}0.121 \\
0.121\end{array}$ & $\begin{array}{l}-0.100 \\
-0.099\end{array}$ & $\begin{array}{l}0.221 \\
0.220\end{array}$ & 0.221 \\
\hline The Rigolets, LA & $\begin{array}{l}30^{\circ} 10^{\prime} \mathrm{N} \\
30^{\circ} 10^{\prime} \mathrm{N} \\
30^{\circ} 10^{\prime} \mathrm{N} \\
30^{\circ} 10^{\prime} \mathrm{N} \\
30^{\circ} 10^{\prime} \mathrm{N} \\
30^{\circ} 10^{\prime} \mathrm{N}\end{array}$ & $\begin{array}{l}89^{\circ} 44.2^{\prime} \mathrm{W} \\
89^{\circ} 44.2^{\prime} \mathrm{W} \\
89^{\circ} 44.2^{\prime} \mathrm{W} \\
89^{\circ} 44.2^{\prime} \mathrm{W} \\
89^{\circ} 44.2^{\prime} \mathrm{W} \\
89^{\circ} 44.2^{\prime} \mathrm{W}\end{array}$ & $\begin{array}{l}\text { BH1160 } \\
\text { BH1164 } \\
\text { BH1163 } \\
\text { BH1537 } \\
\text { BH1538 } \\
\text { BH1539 }\end{array}$ & $\begin{array}{l}\text { PIKE RM } 3 \\
\text { PIKE RESET } \\
\text { C } 193 \\
\text { WES } 16 \\
\text { WES } 15 \\
\text { WES } 14\end{array}$ & $\begin{array}{l}8761402 \\
8761402 \\
8761402 \\
8761402 \\
8761402 \\
8761402\end{array}$ & $\begin{array}{l}0.125 \\
0.125 \\
0.125 \\
0.125 \\
0.125 \\
0.125\end{array}$ & $\begin{array}{l}-0.081 \\
-0.070 \\
-0.086 \\
-0.087 \\
-0.087 \\
-0.086\end{array}$ & $\begin{array}{l}0.206 \\
0.195 \\
0.211 \\
0.212 \\
0.212 \\
0.211\end{array}$ & 0.208 \\
\hline $\begin{array}{l}\text { Rt. 433, Bayou } \\
\text { Bonfouca, LA }\end{array}$ & $\begin{array}{l}30^{\circ} 16.3^{\prime} \mathrm{N} \\
30^{\circ} 16.3^{\prime} \mathrm{N}\end{array}$ & $\begin{array}{l}89^{\circ} 47.6^{\prime} \mathrm{W} \\
89^{\circ} 47.6^{\prime} \mathrm{W}\end{array}$ & $\begin{array}{l}\text { BH1253 } \\
\text { BH1254 }\end{array}$ & $\begin{array}{l}\text { V } 20 \\
\text { W } 20\end{array}$ & $\begin{array}{l}8761473 \\
8761473\end{array}$ & $\begin{array}{l}0.084 \\
0.084\end{array}$ & $\begin{array}{l}-0.148 \\
-0.149\end{array}$ & $\begin{array}{l}0.232 \\
0.233\end{array}$ & 0.233 \\
\hline Chef Menteur, LA & $30^{\circ} 3.9^{\prime} \mathrm{N}$ & $89^{\circ} 48^{\prime} \mathrm{W}$ & BH1133 & E 3145 & 8761487 & 0.170 & -0.042 & 0.212 & 0.212 \\
\hline $\begin{array}{l}\text { Michoud Substation, } \\
\text { ICWW, LA }\end{array}$ & $\begin{array}{l}30^{\circ} 0.4^{\prime} \mathrm{N} \\
30^{\circ} 0.4^{\prime} \mathrm{N}\end{array}$ & $\begin{array}{l}89^{\circ} 56.2^{\prime} \mathrm{W} \\
89^{\circ} 56.2^{\prime} \mathrm{W}\end{array}$ & $\begin{array}{l}\text { BH3007 } \\
\text { BH1083 }\end{array}$ & $\begin{array}{l}\text { WES } 19 \\
\text { D } 276\end{array}$ & $\begin{array}{l}8761678 \\
8761678\end{array}$ & $\begin{array}{l}0.212 \\
0.212\end{array}$ & $\begin{array}{l}0.102 \\
0.090\end{array}$ & $\begin{array}{l}0.110 \\
0.122\end{array}$ & 0.116 \\
\hline
\end{tabular}

offset of $0.211 \mathrm{~m}$ between MSL and NAVD88 as of 2001. From the data available (Fig. 2a), it can be seen that the differences between NAVD88 and MSL are greater in southern Louisiana and less in eastern Louisiana. Therefore, a constant adjustment would tend to slightly underpredict surge in southern Louisiana and overpredict it in eastern Louisiana.

Sea level trends available for three stations in the region [Grand Isle, Louisiana, shown in Fig. 2b; Eugene Island, Louisiana; and Sabine Pass, Texas; NOAA $(2009 a, b)]$ were used to estimate the relative sea level rise from 2001, when the vertical data were reconciled (Table 1; Shields 2003), to 2008, when Hurricane Gustav made landfall in Louisiana. The average value for relative sea level rise at the three stations during this period is $0.057 \mathrm{~m}$.

Steric effects due to thermal expansion of the ocean water are prominent in the Gulf of Mexico. This signal is present in the harmonic constants computed by NOAA for the long-term solar annual (Sa) and semiannual (Ssa) tidal constituents. These harmonic constants were used to compute the amplitude of this effect during the same period of the year as Hurricane Gustav (Table 2, Fig. 2c).
The NOAA sea level record for the year 2008 was also extracted from stations in the area of interest to take into account the state of the ocean during that year. The mean was removed and a 30-day low-pass Gaussian filter was applied, then the average for all stations was calculated (Table 2, Fig. 2c). Both long- and short-term contributions ( 0.081 and $0.114 \mathrm{~m}$, respectively) were averaged to provide an estimate of the seasonal fluctuation in sea level of $0.098 \mathrm{~m}$.

A total vertical reference level adjustment of $0.366 \mathrm{~m}$ was used and comprised the sum of the three individual components discussed above.

\section{b. Asymmetric wind model}

The asymmetric gradient wind model (AWM), described by Mattocks and Forbes (2008), was used to generate wind fields for the storm surge forecasts and hindcast simulations of Hurricane Gustav. The AWM is based on the Holland (1980) gradient wind model with the added feature that the radius of maximum winds $\left(R_{\max }\right)$ varies azimuthally around the cyclone to capture the asymmetry in the shape of the storm. The tangential velocity is derived from the pressure field, assuming the 

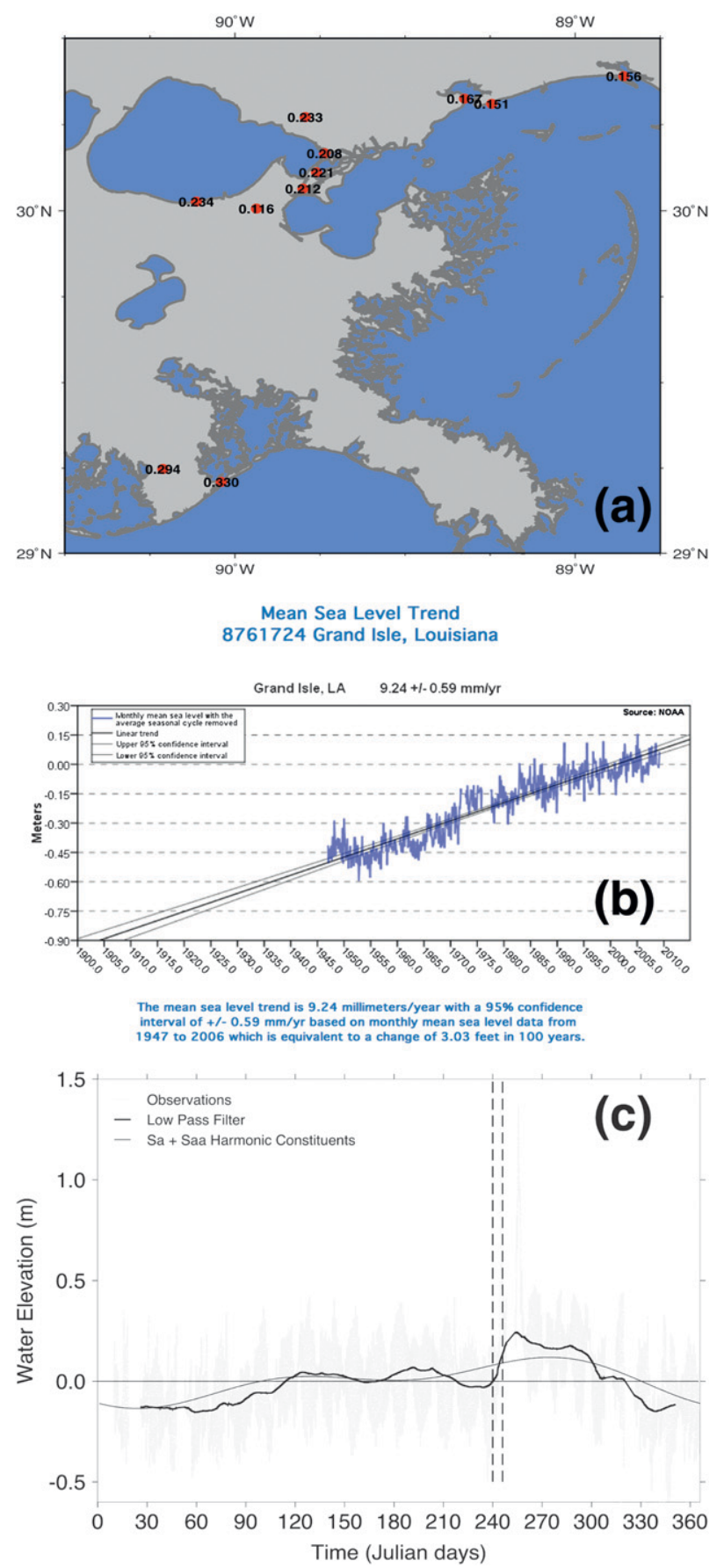

FIG. 2. (a) Map of the difference ( $\mathrm{m}$ ) between the MSL and NAVD88 vertical data computed from CO-OPS/NGS elevation data; (b) the MSL trend at station 8761724 (Grand Isle, LA), which shows an increase in MSL of $9.24 \mathrm{~mm} \mathrm{yr}^{-1}$ with a $95 \%$ confidence interval of $\pm 0.59 \mathrm{~mm} \mathrm{yr}^{-1}$ (figure reprinted from NOAA 2009a); (c) NOAA water elevation $(\mathrm{m})$ relative to MSL at Grand Isle (light gray), 30-day Gaussian low-pass filtered water elevation signal (solid black line), and combined amplitude of the Ssa and Sa tidal constituents (dark gray solid line) for 2008. The simulation time period is bounded by the two vertical dashed lines.
TABLE 2. Steric height corrections $(\mathrm{m})$ relative to MSL for the 28 Aug-2 Sep 2008 storm period from long- and short-term calculations.

\begin{tabular}{lcc}
\hline \hline \multicolumn{1}{c}{ Station } & $\begin{array}{c}\text { Long-term correction } \\
(\mathrm{m})(\text { Sa }+ \text { Saa tidal } \\
\text { constituents })\end{array}$ & $\begin{array}{c}\text { Short-term correction } \\
(\mathrm{m})(30 \text {-day } \\
\text { low-pass filter })\end{array}$ \\
\hline Pilot Station & 0.073 & 0.110 \\
Port Fourchon & 0.107 & 0.150 \\
Grand Isle & 0.087 & 0.082 \\
Calcassieu Pass & 0.059 & - \\
Average & 0.081 & 0.114 \\
Combined average & 0.098 & \\
\hline
\end{tabular}

winds are in gradient wind balance. Thus, when the tangential acceleration vanishes and the flow is parallel to the isobars, the equation that describes a three-way balance between the pressure gradient and the centrifugal and Coriolis forces can be inverted and solved to obtain the tangential 1-min wind velocity $\left(V_{\text {asym }}\right)$ valid at the top of the boundary layer:

$$
\begin{aligned}
V_{\text {asym }}= & \sqrt{\frac{B}{\rho_{a}}\left[\frac{R_{\max }(\theta)}{r}\right]^{B}\left(P_{b}-P_{c}\right) e^{-\left[R_{\max }(\theta) / r\right]^{B}}+\left(\frac{r f}{2}\right)^{2}} \\
& -\left(\frac{r f}{2}\right)
\end{aligned}
$$

where $R_{\max }$ is a function of the azimuthal angle $\theta, \rho_{a}$ is the density of the air, $f=2 \Omega \sin$ (latitude) is the Coriolis force, $\Omega$ is the rotational frequency of the earth, $r$ is the radial distance from the storm center, $B$ is the Holland shape parameter, and $P_{b}$ and $P_{c}$ are the background and central pressures, respectively.

Since the AWM model is extremely computationally efficient, the winds can be generated "on the fly" during the simulation-no precalculation or storage of large gridded wind fields is required. The winds are calculated exactly at ADCIRC grid node locations, directly coupled to the ocean model at every time step, thereby eliminating interpolation artifacts that can occur when gridded vortex wind fields are interpolated in space and time. Here, $R_{\max }$, which varies with quadrant and forecast time, is computed dynamically at each time step from the significant radii of the 1-min sustained 51.4, $32.9,25.7$, or $17.5 \mathrm{~m} \mathrm{~s}^{-1}(100,64,50$, or $34 \mathrm{kt})$ isotachs in the four quadrants of the storm. The NHC forecast advisories provide wind speeds for the entire forecast period; however, wind radii are only provided for the first $72 \mathrm{~h}$. Therefore, the radii after $72 \mathrm{~h}$ were persisted for the remainder of the forecast. The Holland shape parameter, $B$, which determines the steepness of the eyewall and the strength of the winds far from the center, is computed dynamically at each time step and is dependent 
TABLE 3. Advisory number, day, and time of best-track and forecast advisories and duration of the forecast simulations.

\begin{tabular}{|c|c|c|c|}
\hline Advisory No. & Best-track date (UTC) & Advisory/OFCL date (UTC) & Length of simulation (days) \\
\hline 15 & 120028 Aug 2008 & 150028 Aug 2008 & 5 \\
\hline 16 & 180028 Aug 2008 & 210028 Aug 2008 & 5.125 \\
\hline 17 & 000029 Aug 2008 & 030029 Aug 2008 & 5.5 \\
\hline 18 & 060029 Aug 2008 & 090029 Aug 2008 & 5.75 \\
\hline 19 & 120029 Aug 2008 & 150029 Aug 2008 & 5.75 \\
\hline 20 & 180029 Aug 2008 & 210029 Aug 2008 & 5.25 \\
\hline 21 & 000030 Aug 2008 & 030030 Aug 2008 & 5.5 \\
\hline 22 & 060030 Aug 2008 & 090030 Aug 2008 & 5.75 \\
\hline 23 & 120030 Aug 2008 & 150030 Aug 2008 & 5 \\
\hline 24 & 120030 Aug 2008 & 180030 Aug 2008 & 5 \\
\hline 25 & 180030 Aug 2008 & 210030 Aug 2008 & 5.25 \\
\hline 26 & 000031 Aug 2008 & 030031 Aug 2008 & 5.5 \\
\hline 27 & 060031 Aug 2008 & 090031 Aug 2008 & 4.75 \\
\hline 28 & 120031 Aug 2008 & 150031 Aug 2008 & 5 \\
\hline 29 & 180031 Aug 2008 & 210031 Aug 2008 & 4.75 \\
\hline 30 & 00001 Sep 2008 & 03001 Sep 2008 & 5 \\
\hline 31 & 06001 Sep 2008 & 09001 Sep 2008 & 5.25 \\
\hline 32 & 12001 Sep 2008 & 15001 Sep 2008 & 5 \\
\hline 33 & 18001 Sep 2008 & 21001 Sep 2008 & 4.75 \\
\hline 34 & 00002 Sep 2008 & 03002 Sep 2008 & 5 \\
\hline Best track & 06002 Sep 2008 & & 4.75 \\
\hline
\end{tabular}

upon the maximum wind speed, whose location is uncertain. We assume $B$ to be constant in all quadrants. The winds were modified by the land surface characteristics through incorporation of a directionally dependent surface roughness length that takes into account the land cover upwind and sheltering due to forest canopy (Westerink et al. 2008).

\section{Forecast simulations}

\section{a. Hurricane Gustav}

Hurricane Gustav forecast simulations were initiated at 1200 UTC on 28 August 2008, 5 days before the predicted landfall. The simulations were cold started using a hyperbolic tangent ramp function to prevent model initialization shock, to allow the spinup transients to dissipate, and to achieve full wind forcing after $6 \mathrm{~h}$.

Information from the NHC forecast advisory/official (OFCL) tracks was used for the forecast period, while best-track data were used for the hindcast period. The forecasts use only information available from NHC forecast advisories, plus general assumptions that are used in real-time forecast systems. Pressure trends were derived from previous storms in the Gulf of Mexico for strengthening and weakening storm phases. These trends were used to calculate the central pressure in the forecasts, which is not available in the NHC forecast advisories. The best-track storm positions are issued at 0000 , 0600, 1200, and 1800 UTC cycles while the forecast advisories are issued at 0300, 0900, 1500, and 2100 UTC, staggered in time with respect to the best-track data. The hurricane eye locations are linearly interpolated in time in between NHC-issued track positions. Table 3 shows the days and times of the best-track data and forecast advisories and the duration of the forecast simulations. The best-track information was used only for the period before the advisory time. Thus, a simulation of a specific forecast advisory number is comprised of the NHC best track starting from 1200 UTC on 28 August up to the last time prior to the forecast advisory, followed by the specified forecast advisory track information.

\section{b. Forecast track locations}

Figure $3 \mathrm{a}$ shows the 20 different tropical cyclone forecast tracks and the best track, with colors denoting the advisory number. The track predictions are quite consistent; all show the storm advancing toward the northwest across the Gulf of Mexico. Zooming in on southeastern Louisiana (Fig. 3b), the 20 forecast tracks show a spread of approximately $60 \mathrm{~km}$ in the landfall location. This is well within the NHC 5-yr average forecast error in storm track used to define the "cone of uncertainty" (NHC 2008). The smallest NHC official mean (2005-2009) cone of uncertainty is $62 \mathrm{~km} \mathrm{(34} \mathrm{n} \mathrm{mi)} \mathrm{for}$ a 12-h forecast. The cones of uncertainty for all other forecast times are much larger. If one visually compares the forecast storm tracks of Hurricane Gustav with those of Hurricane Ike (Forbes et al. 2010), the latter seems a more erratic, more difficult storm to forecast. However, the OFCL forecast track error computed by NHC is actually higher for Gustav (Beven and Kimberlain 


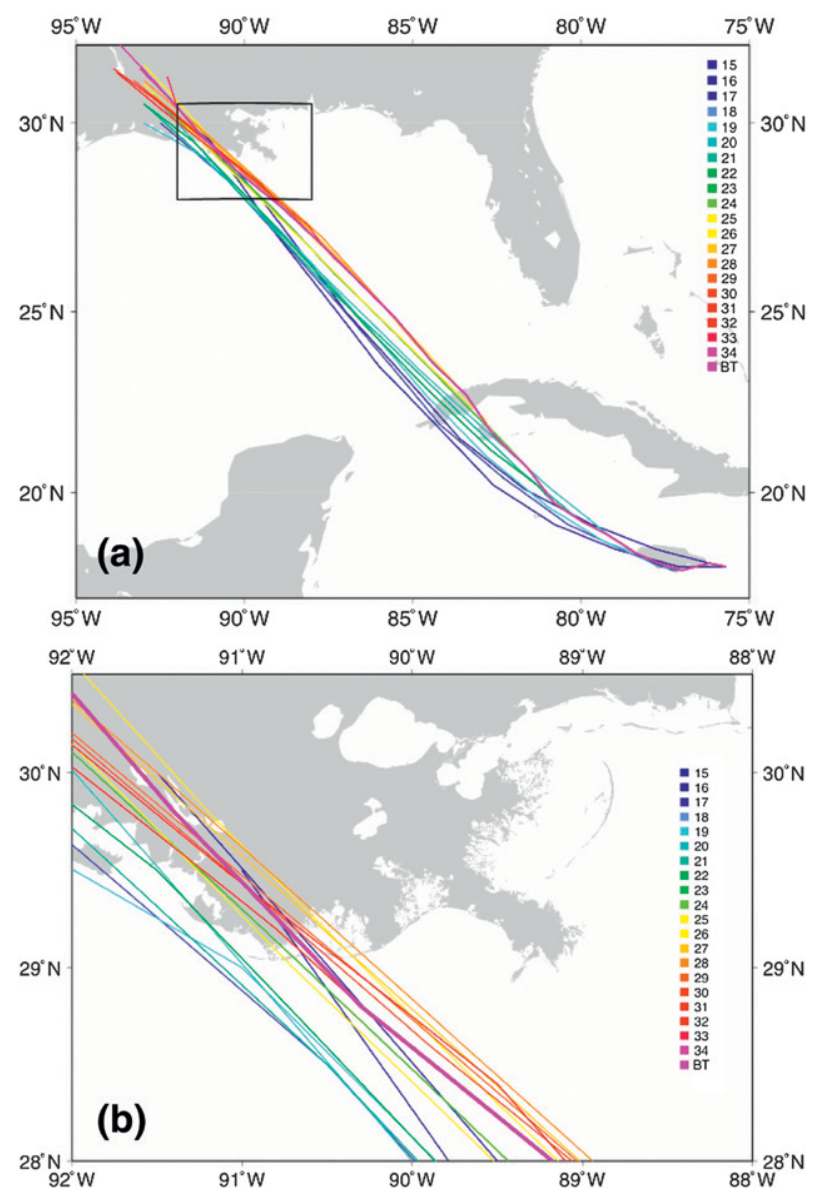

FIG. 3. (a) NHC forecast tracks for Hurricane Gustav (2008) with colors denoting the advisory number. (b) As in (a), but zooming in on the southern LA area.

2009) from forecast hours 12 to 96 than for Ike (Berg 2009). The forecast track error for $120 \mathrm{~h}$ is the only instance in which the track error for Hurricane Gustav is less than the track error for Hurricane Ike.

The distance between each of the advisory tracks and the best track at $29^{\circ} \mathrm{N}$ was calculated (Fig. 4). The forecast tracks from earlier advisories lie to the west of the best track while, beginning with track 26 (36 h before landfall), they lie mainly to the east of the best track.

\section{c. Forecast wind speeds and storm size}

Figure 5a shows the evolution of the maximum 1-min sustained wind speed $\left(\mathrm{V}_{\max }\right)$ with latitude for the different forecast advisories. The values of $V_{\max }$ for the intermediate advisories reach $72 \mathrm{~m} \mathrm{~s}^{-1}$. During earlier and later advisories, the maximum wind speeds hover around $50-55 \mathrm{~m} \mathrm{~s}^{-1}$. The $V_{\max }$ of the best track is larger than earlier advisories for lower latitudes and substantially lower for latitudes greater than $26^{\circ} \mathrm{N}$. At landfall, $V_{\max }$ decays abruptly. Figure $5 \mathrm{~b}$ shows the evolution of

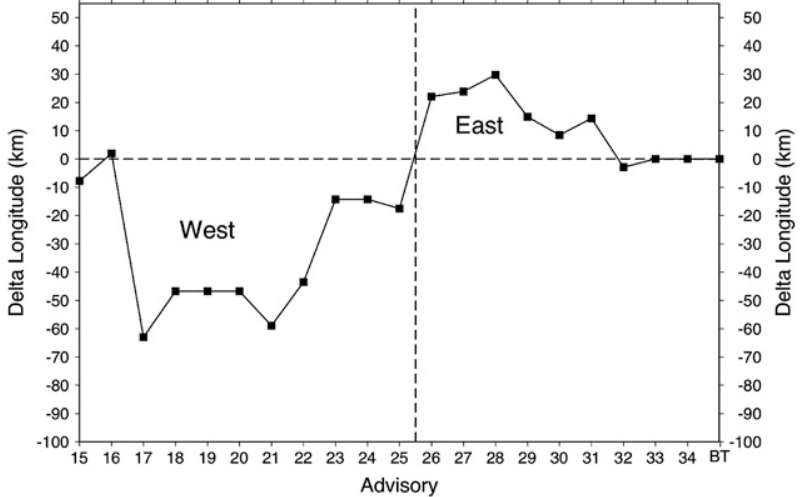

FIG. 4. Forecast track shift $(\mathrm{km})$ and eventual track convergence with respect to the best track at $29^{\circ} \mathrm{N}$. The dashed vertical line separates the forecast tracks from earlier advisories, which lie to the west of the best track, and the forecast tracks from later advisories, which lie to the east of the best track.

the storm size [radius of maximum wind speed, $R_{\max }$, in the right-front quadrant (RFQ)] with latitude for the different advisories calculated by the AWM. As the storm approaches landfall (approximately $29^{\circ} \mathrm{N}$ ), all of the forecasts predict weakening (decreasing $V_{\max }$ ) and growth in size (increasing $R_{\max }$ ), which is typical for storms approaching land in this region (FEMA 2008). The $R_{\max }$ for the best track is larger than earlier advisories and remains larger for most advisories. It first decreases in size at landfall and then increases in size after landfall, though not as much as the forecast advisories predicted.

\section{Forecast surge}

The forecast surge response is evaluated by first determining the maximum event water surface elevation (also called the envelope of highest water or EOHW) at each node in the computational grid for each of the 20 forecast advisories. The average (section 4a), minimum and maximum of the maxima surface elevation (section $4 b$ ) provide a quantitative measure of the mean maximum surface elevation and the envelope or range of the possible inundation scenarios that could occur with the different advisories and, therefore, provide the mean and best- and worst-case scenarios for which a threatened coastal community should prepare. The EOHW values are compared for four selected advisories (section 4c) and between ensembles of advisories (section 4d) to characterize the surge variability over the 5 days of forecasts.

As a point of reference for the forecast advisory evaluation, the maximum surge generated using the best track is presented in Fig. 6a. Water driven across Chandeleur Sound and Lake Borgne produces a high surge in the funnel-shaped region to the east of New Orleans. 

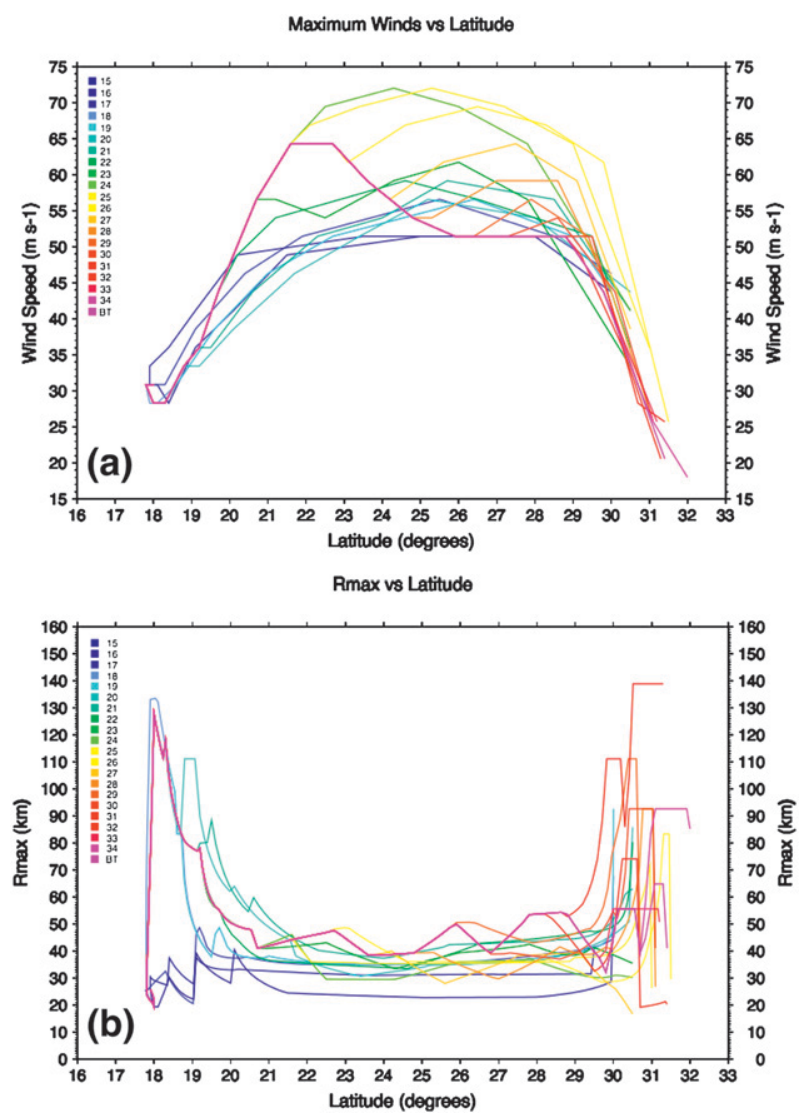

FIG. 5. (a) Evolution of maximum 1-min sustained wind speed ( $\mathrm{m} \mathrm{s}^{-1}$ ) with latitude for different advisories. (b) Evolution of $R_{\max }$ $(\mathrm{km})$ in the right front quadrant (RFQ) with latitude for different advisories. Colors represent advisory number, color-coded from blue (advisory 15) to magenta (best track). Best track is denoted by BT.

High-water elevations are generated to the southwest of Breton Sound along the Mississippi River, with amplification southeast of New Orleans at English Turn. This is related to the fairly uniform easterly winds driving a steady state set up to the east of the river, which changes once the storm passes (Resio and Westerink 2008; Dietrich et al. 2010). High elevations also occur to the west of Barataria Bay and penetrate inland in areas east of Highway 1.

Figure $6 \mathrm{~b}$ shows the wind swath produced by the AWM. Ten-minute wind speeds higher than $45 \mathrm{~m} \mathrm{~s}^{-1}$ extend approximately $60 \mathrm{~km}$ to the east of the storm track. Computations at exact ADCIRC node locations and at fine temporal resolution create smoothly varying wind fields over the ocean. The dark blue areas on land indicate areas where the model assumes the surface wind speed is zero due to the presence of sheltering from a substantial forest canopy (Westerink et al. 2008).

A more detailed discussion of the best-track results is presented in section 5 .
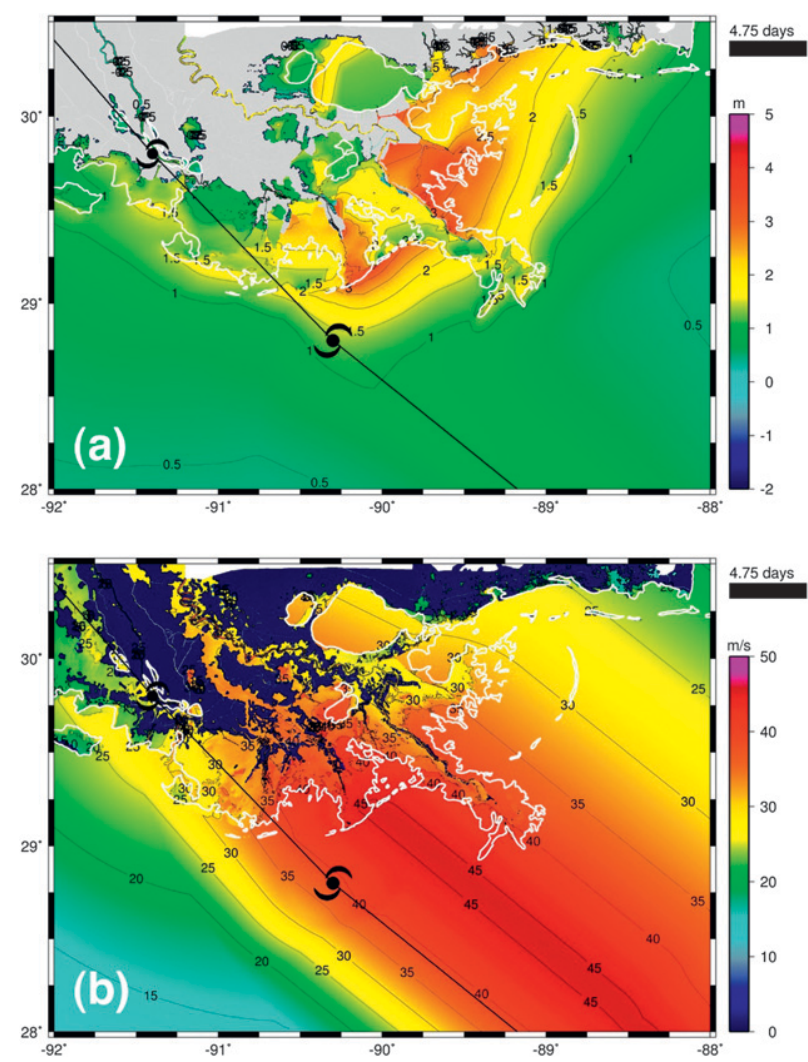

FIG. 6. (a) Maximum water surface elevation (m) relative to NAVD88 and (b) maximum wind speed $\left(\mathrm{m} \mathrm{s}^{-1}\right)$ produced by the asymmetric gradient wind model (AWM) using NHC best-track storm track information.

\section{a. 20-advisory, ensemble-averaged maximum surge}

Figure $7 \mathrm{a}$ shows the ensemble-averaged maximum event elevation over the full set of 20 forecast advisories. This ensemble-averaged surge exceeds $1.5 \mathrm{~m}$ throughout most of coastal Louisiana, with maximum surge occurring against land or engineered structures that face toward the southeast. East of the Mississippi River Delta, the ensemble average reaches approximately $3 \mathrm{~m}$ in the funnel-shaped region at the entrance to the Intracoastal Waterway (ICWW) to the east of New Orleans and in the Caernarvon marsh to the northwest of Breton Sound. Surge also accumulates against the land bridge-railroad bed that separates Lakes Borgne and Pontchartrain, the western Mississippi coastline, and the western end of Lake Pontchartrain. Comparable ensemble-averaged surge also occurs west of the Mississippi delta seaward of Grand Isle and north of Timbalier and Terrebonne Bays.

\section{b. 20-advisory, ensemble minimum and maximum surge}

The ensemble minimum of the maximum elevations (Fig. 7b) is spatially similar to, but about $1 \mathrm{~m}$ lower than, 


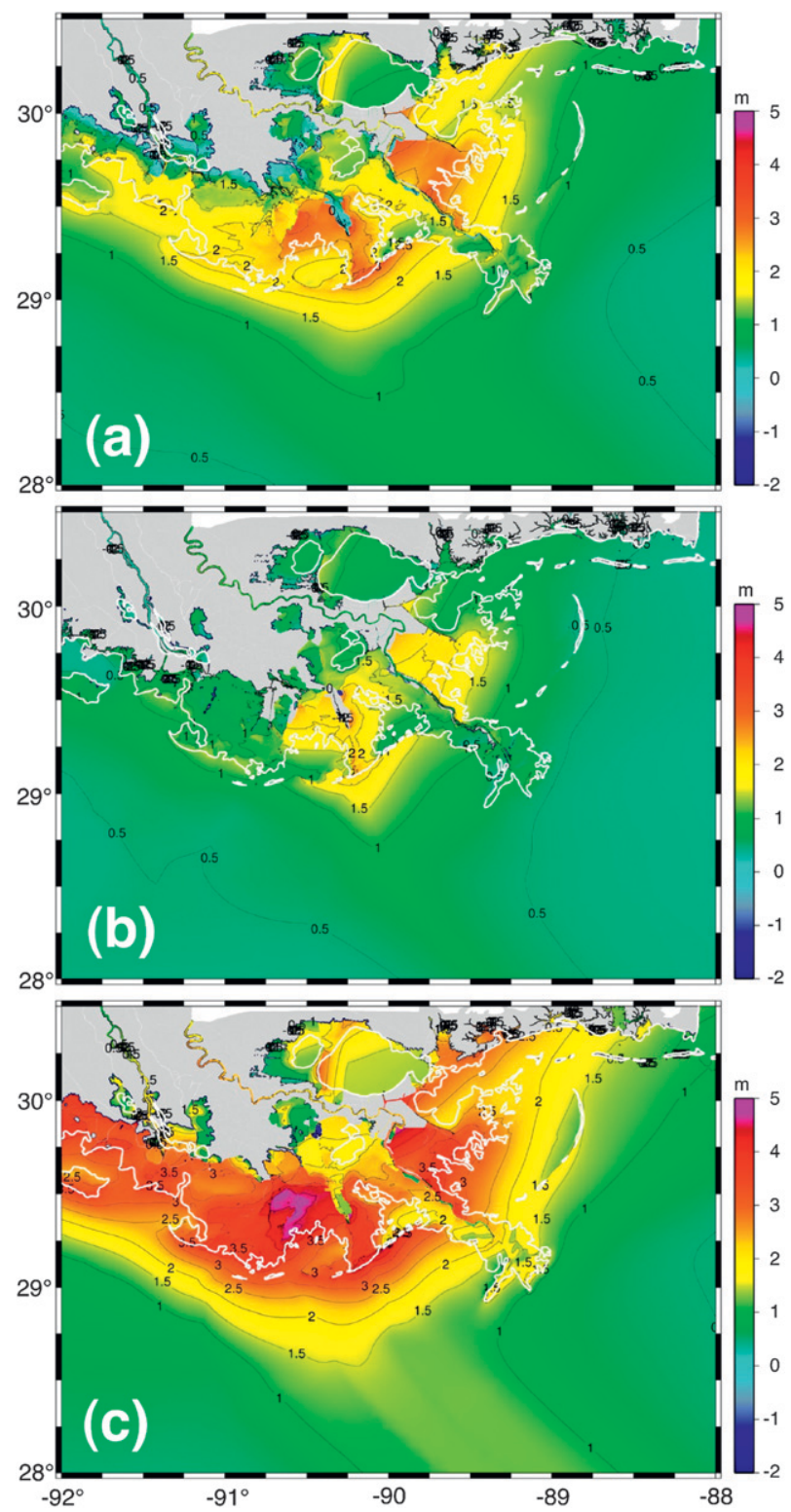

FIG. 7. (a) Average, (b) maximum, and (c) minimum of the maximum event water surface elevation $(\mathrm{m})$ relative to NAVD88 of the poststorm ensemble of 20 forecasts.

the ensemble-averaged surge throughout much of the region. These lowest maximum surge values also occur against southeastward-facing topography to the northwest of Breton Sound, seaward of Grand Isle, and in the sounds north of Grand Isle. Even for this most favorable set of responses, there is still significant inundation, with surge as high as $2.5 \mathrm{~m}$.

The maximum of the maximum event elevations for the 20-forecast advisory ensemble (Fig. 7c) exhibits a spatial pattern similar to the ensemble-averaged surge, with highest surge along southeast-facing topography

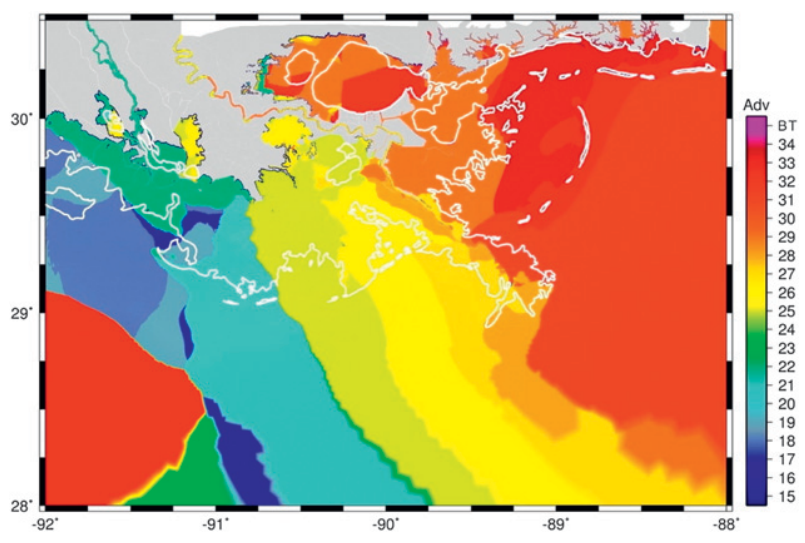

FIG. 8. Geographical map that shows which ensemble member (advisory number) contributes to the maximum water surface elevation.

and values about $1 \mathrm{~m}$ greater than the ensemble-averaged surge. The ensemble maximum surge is greatest northwest of Terrebonne Bay, where it reaches approximately $5 \mathrm{~m}$. The ensemble maximum surge indicates significant surge west of the actual storm track in the Atchafalaya Bay and Vermillion Bay regions $\left(91^{\circ}-92^{\circ} \mathrm{W}\right)$. Earlier advisories predicted storm tracks that were well to the west of the actual track (Fig. 4), generating significant surge in these areas, while the later advisory tracks kept these areas generally on the west, low-surge side of the storm. This yielded high ensemble maximum surges but substantially lower ensemble-averaged surge.

The ensemble member (forecast advisory number) that contributes to the 20 -advisory, ensemble maximum event elevation at each node in the computational grid was identified (Fig. 8). In general, earlier advisories contribute to the maximum surge in western Louisiana, while later advisories produce maximum elevations in Lake Pontchartrain and along most of the eastern coastline. This is consistent with the general west-to-east progression of the predicted storm tracks (Fig. 4). There is one notable exception in the southwest corner of Fig. 7 , where there is a contribution to the maximum surface water elevation by advisory 32 associated with a large $R_{\max }$ (Fig. 5b) and higher wind intensity.

Overall, for the 20-forecast advisory ensemble there is a range in surge of approximately $4 \mathrm{~m}$ in western Louisiana and $2 \mathrm{~m}$ throughout much of the rest of the region.

\section{c. Surge sensitivity to track location, storm intensity, and size}

Comparisons of maximum surge produced by four selected forecast advisories are presented and compared to the surge computed using the best track to illustrate the sensitivity to variations in storm parameters. 


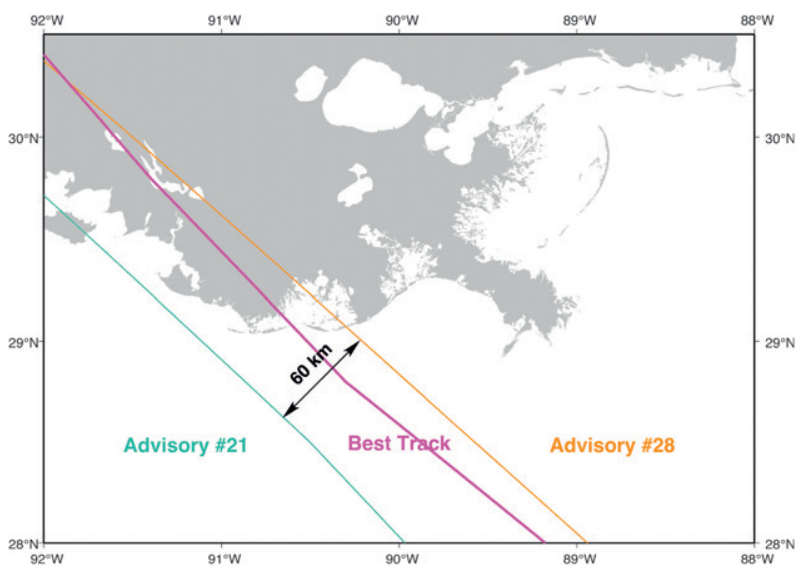

FIG. 9. Tracks for advisories 21 (green line) and 28 (orange line), the members of the forecast ensemble that strayed farthest to the west and east, respectively, of the best track (magenta line).

The storm tracks for advisories 21 and 28 are separated by about $60 \mathrm{~km}$ at landfall and bracket the best track (Fig. 9). Both had similar sizes and intensities but their tracks were to the left and to right of the best track, respectively. They are used as examples to demonstrate the impact of track location. The western track (advisory 21) generated substantial surge and inundation west of the Mississippi Delta, north and west of the Terrebonne
Bay area, and along the western Louisiana coastline, reaching $4 \mathrm{~m}$ in magnitude (Fig. 10a) and overpredicting the surge associated with the best track by up to $3 \mathrm{~m}$ in this region (Fig. 11a). The $R_{\max }$ calculated by the AWM for this advisory ranges from $40-48 \mathrm{~km}$ in the RFQ to $27-31 \mathrm{~km}$ in the right-rear quadrant (RRQ) of the storm. Thus, the strongest onshore winds occur west of the delta and along the western Louisiana shoreline. The lateral extent of the storm is large enough that significant surge also occurs east of the delta in Breton Sound and in the funnel region, although this is up to $1 \mathrm{~m}$ less than that due to the best track.

The $60-\mathrm{km}$ shift in track location of advisory 28 focuses much stronger onshore winds east of the Mississippi River and only creates onshore winds along the western Louisiana shoreline from the back side of the storm, after it had weakened considerably. Consequently, surge is greatest east of the Mississippi delta, in the area northwest of Breton Sound, in the funnel region, and between Lakes Borgne and Pontchartrain (Fig. 10b). The maximum elevations are much lower than those produced by advisory 21 in western Louisiana. These compare reasonably well with the best track, with typical differences of $1 \mathrm{~m}$ or less (Fig. 11b). The $R_{\max }$ calculated by the AWM ranges from $30-41 \mathrm{~km}$ in the RFQ to $18-30 \mathrm{~km}$ in the RRQ.

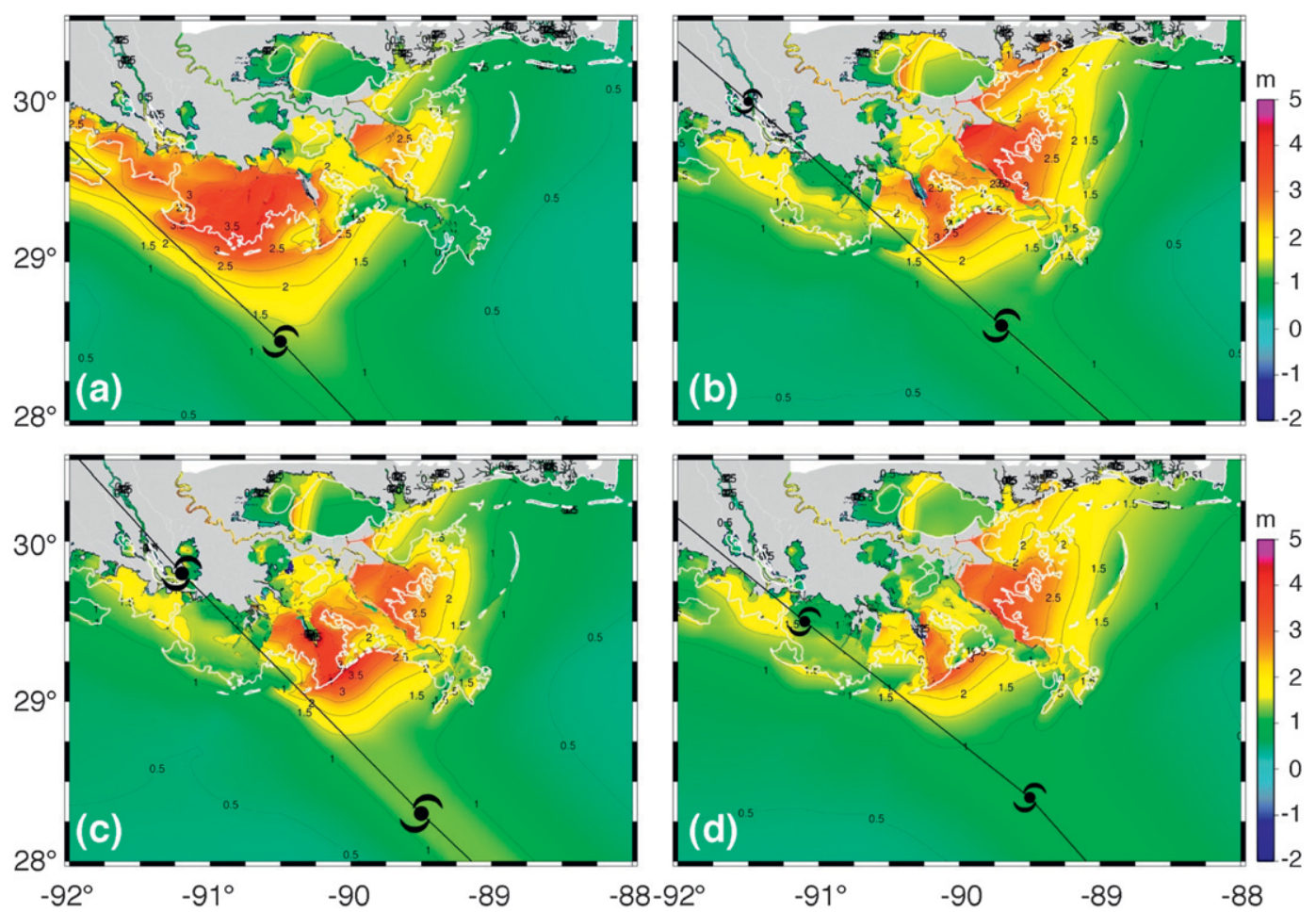

FIG. 10. Maximum water surface elevation (m) for advisories (a) 21, (b) 28, (c) 26, and (d) 31. The track location is depicted by the black line and the eye location by the hurricane icon. 

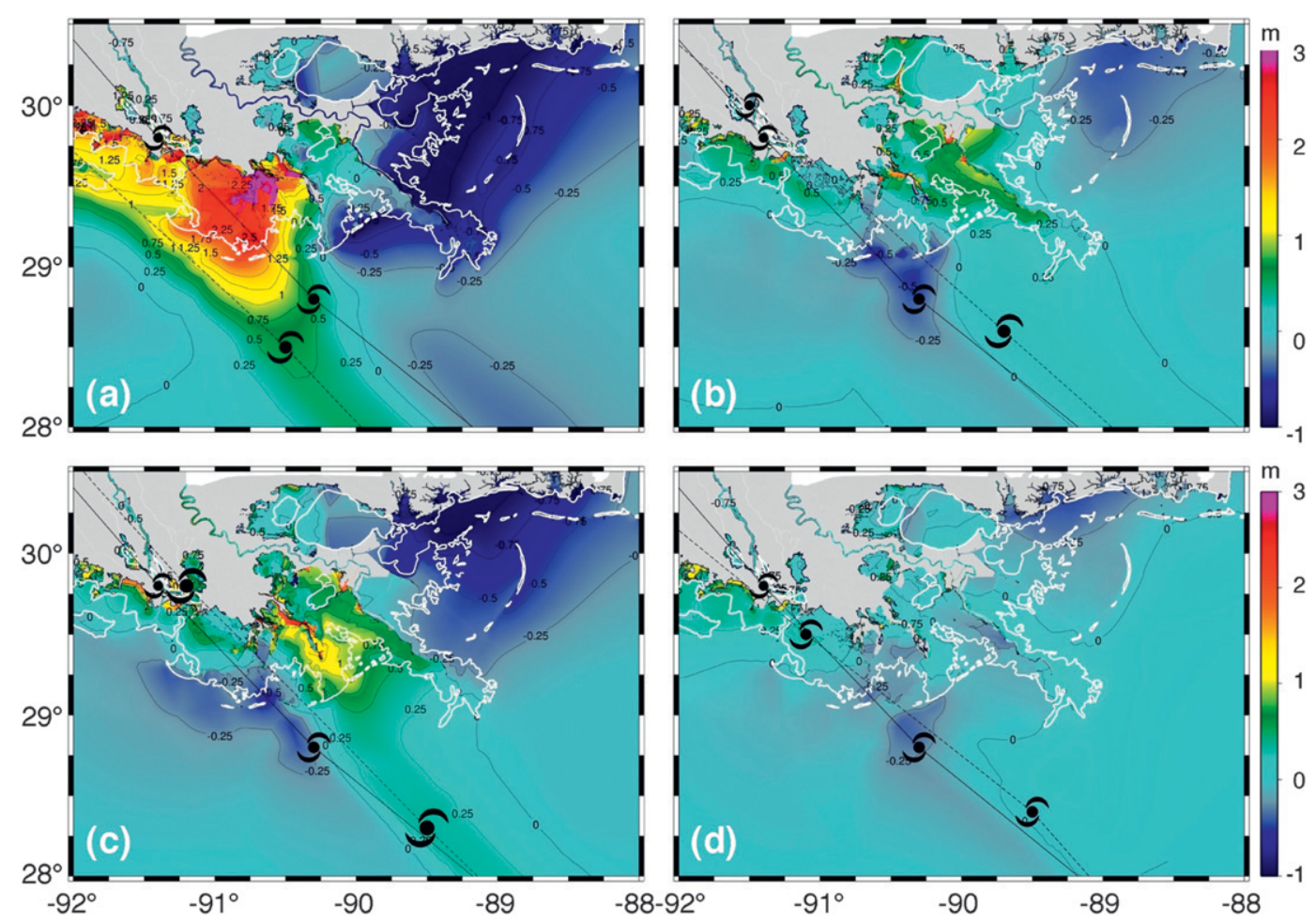

FIG. 11. Difference between the maximum water surface elevation (m) for (a) advisory 21 - best track, (b) advisory 28 - best track, (c) advisory 26 - best track, and (d) advisory 31 - best track. The best track is depicted by solid black lines, advisory tracks by dashed lines, and eye locations by hurricane icons.

Advisories 26 and 31 were selected to evaluate the impacts of wind intensity and storm size on the surge. The track locations are both close to, but to the right of, the best track. The maximum 1-min sustained wind speeds, $V_{\max }$, for advisories 26 and 31 are 67 and $51 \mathrm{~m} \mathrm{~s}^{-1}$, respectively, while their radii of maximum winds $R_{\max }$ in the RFQ are 35 and $54 \mathrm{~km}$. The surge produced by advisory 31 (Fig. 10d) is lower in magnitude but extends more toward the eastern Louisiana coast than the surge generated by advisory 26 (Fig. 10c) due to the larger $R_{\max }$ in the former. Advisory 26 produced a surge distribution similar to advisory 28 but it was higher closer to the storm track. The smaller, stronger storm produced by advisory 26 typically generates $0.5-1-\mathrm{m}$ higher surge than the best track immediately east of the storm track and approximately the same amount less than the best track farther to the east. Advisory 31 is comparable to the best track both in track location and storm parameters; thus, its surge is within $0.5 \mathrm{~m}$ of the best track.

In summary, when the sizes of the storm and wind speeds are comparable (Figs. 10a and 10b), the maximum elevation is mostly driven by track orientation with surges deviating more than $3 \mathrm{~m}$ from the surge produced by the best-track data. Smaller and stronger storms produce higher maximum elevations close to the right side of the track, while weaker larger storms produce surges extending over larger areas on the right side of the storm (Figs. 10c and 10d).

\section{d. Forecast ensemble convergence}

Differences between the maximum and minimum of the maximum elevations for ensembles consisting of the final 20,15, 10, and 5 forecast advisories plus the best track were computed to examine the ensemble spread and the evolution of the forecast convergence (Fig. 12). Even though advisories 33 and 34 were issued after landfall when the storm was inland, the trailing rearquadrant wraparound winds continued to create a significant amount of surge to the east of the storm. It is important to include them in the ensemble because they induced maxima in the surface water elevation in areas where the other advisories did not. Advisory 33 caused large maximum inundation areas to the west of the Chandeleur Islands, as seen in Fig. 8. Advisory 34 caused smaller, more localized maxima.

Surge differences in excess of $3 \mathrm{~m}$ occur in the 21- and 16 -member ensembles west of $90.5^{\circ} \mathrm{W}$ while surge differences up to 2 and $1 \mathrm{~m}$, respectively, exist throughout much of the remainder of the domain. The surge 

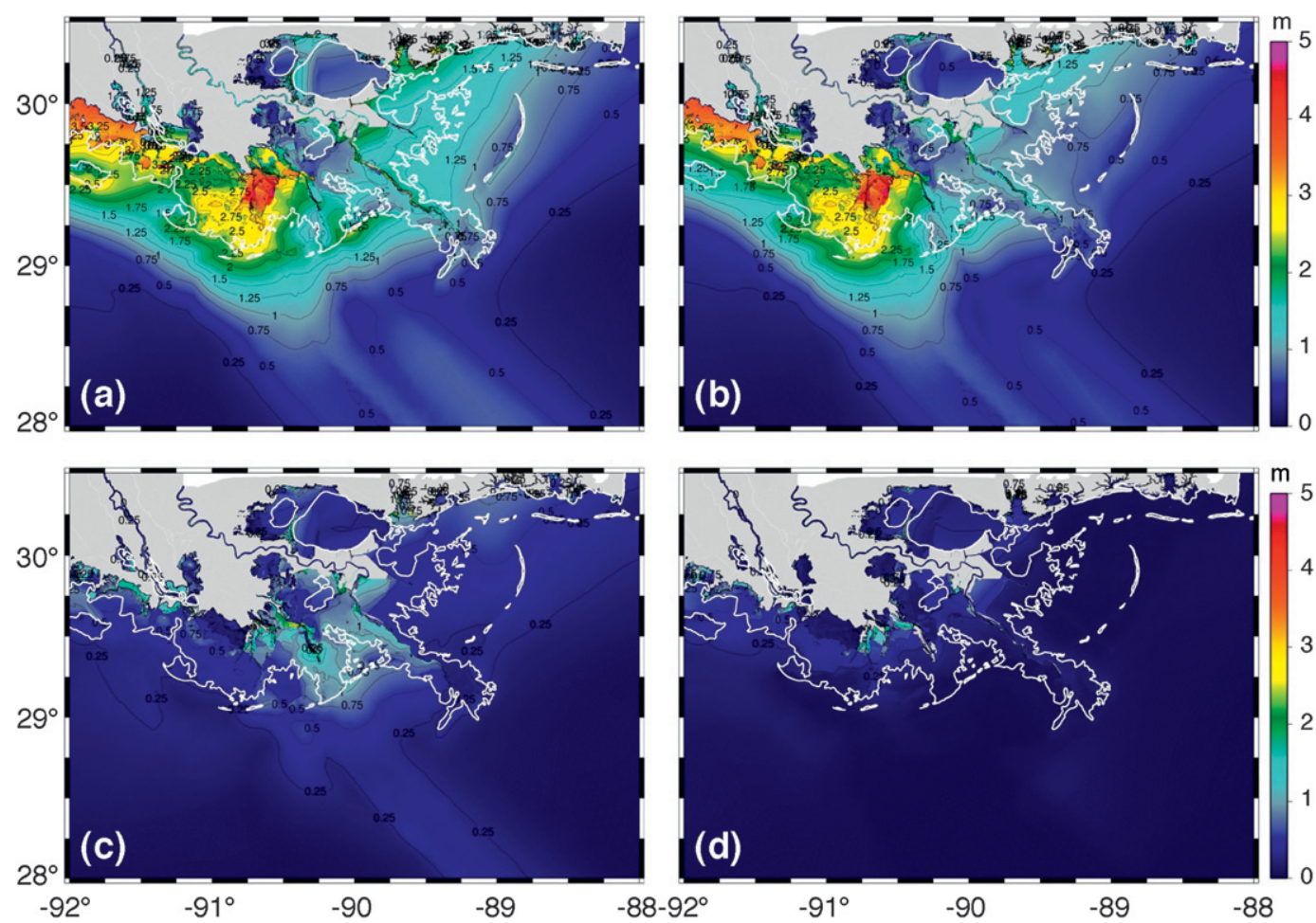

FIG. 12. Differences between the maxima of all maxima and the minima of all maxima of water surface elevation $(\mathrm{m})$ for different numbers of ensemble members: (a) 21, (b) 16, (c) 11, and (d) 6 .

variability is reduced significantly in the $11-$ and 6 member ensembles, typically to values under 1 and $0.3 \mathrm{~m}$, respectively. The 11-member ensemble combines the final 2.5 days of forecast advisories.

The root-mean-square (RMS) difference in maximum water elevation between each advisory and the best track (Fig. 13) was calculated at each model node with depths less than $10 \mathrm{~m}$ for each forecast simulation over the area depicted in Fig. 1. The RMS difference remains approximately constant with each forecast advisory until advisory 23 , where it diminishes sharply and falls to a value of approximately $51 \mathrm{~cm}$. Thereafter, it declines gradually (with the exception of advisory 25 when Gustav made landfall in western Cuba) with a downward trend of $-18.6 \mathrm{~cm} \mathrm{day}^{-1}$. These analyses indicate continued systematic improvement in the surge convergence as the storm nears landfall. This finding is closely tied to the consistency and accuracy of the NHC track forecasts during this period and may not be typical for other storms.

\section{Hindcast simulations}

Hindcast simulations of Hurricane Gustav were carried out by 1) ramping up the flow through the Mississippi and Atchafalaya Rivers, 2) incorporating tidal forcing, and 3) using three different types of wind forcing: (a) AWM wind fields generated from the NHC best-track information for the storm, (b) $\mathrm{H}^{*}$ Wind analyses, and (c) North American Mesoscale (NAM) model winds.

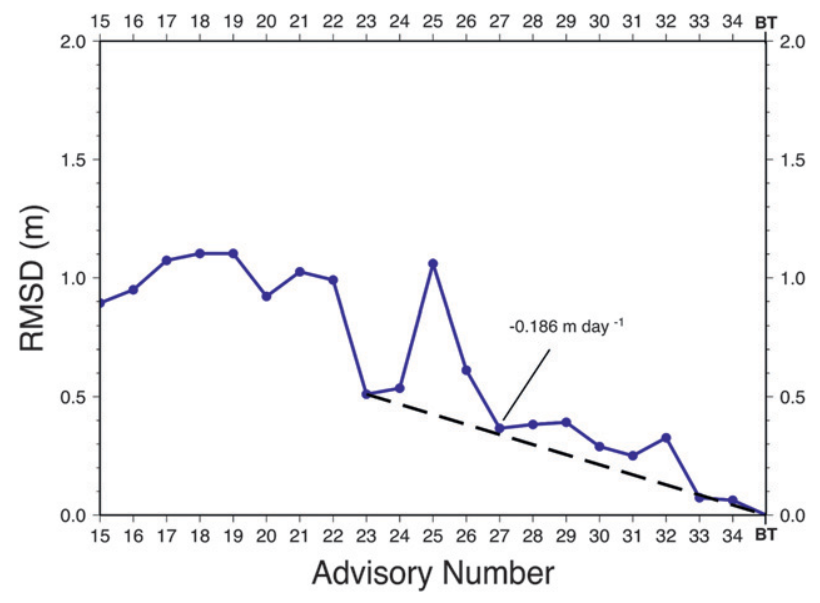

FIG. 13. RMS difference in maximum water elevation between each advisory and the best track at each model node for depths less than $10 \mathrm{~m}$ for each forecast simulation over the area depicted in Fig. 1. 


\section{a. Specification of river fluxes}

The Mississippi and Atchafalaya Rivers are specified via their fluxes into the ADCIRC grid domain (Bunya et al. 2010). The invocation of a wave radiation boundary condition (Flather and Hubbert 1990) allows waves to propagate out of the domain (Luettich and Westerink 2003; Westerink et al. 2008). A river spinup period of 2 days, using a half-day hyperbolic tangent ramp, was activated before tides and wind forcing were applied. This allows the rivers to achieve a steady state and the full river stage to be defined at the boundaries before interactions with other types of forcing occur.

\section{b. Incorporation of tides}

Eight primary lunar and solar tidal harmonic constituents $\left(M_{2}, S_{2}, N_{2}, K_{2}, K_{1}, O_{1}, P_{1}\right.$, and $\left.Q_{1}\right)$ were included in the simulations. These tidal constituents were specified at the open boundary at $60^{\circ} \mathrm{W}$ and as tidal potentials in the interior of the domain. The nodal factors and equilibrium arguments for the tidal constituents were calculated for the beginning of the simulation on 1 July 2008. The complete river and tidal spinup simulation was run from 0000 UTC 1 July 2008 to 1200 UTC 28 August 2008. After the rivers were spun up for 2 days, a tidal spinup using a 10-day hyperbolic tangent ramp was applied to minimize the transient oscillations produced by the initialization. Then, tidal simulations were continued until the onset of the Hurricane Gustav wind forcing at 1200 UTC 28 August 2008.

\section{c. Asymmetric wind model}

Hindcast simulations were computed using the AWM described in section $2 \mathrm{~b}$ and the NHC best-track information for Hurricane Gustav.

\section{d. $H^{*}$ Wind}

The $\mathrm{H}^{*}$ Wind analysis, a product developed by NOAA's Hurricane Research Division, fuses observations from a wide variety of platforms to generate a rendition of the horizontal distribution of wind speeds in a hurricane. Analyses are produced by compositing (cubic Bspline interpolating) all observations available in a given time window relative to the storm center onto an $8^{\circ} \times 8^{\circ}$ grid. Observations include airborne sensors, offshore monitoring stations, land-based radar, and meteorological stations [U.S. Air Force and NOAA aircraft, ships, buoys, Coastal-Marine Automated Network (C-MAN) platforms, and surface airways]. All data are quality controlled, then processed to conform to a common framework for height $(10 \mathrm{~m})$, exposure (marine or open terrain/overland), and averaging period (maximum sustained 1-min wind speed). Several hours of observations are usually required to provide sufficient data density and coverage for an analysis (Powell et al. 1998). In general, The $\mathrm{H}^{*}$ Wind analyses provide the most accurate renditions of the winds at locations where wind measurements are available, but suffer from data sampling gaps when coverage is poor (e.g., lack of reconnaissance aircraft flights or dropwinsondes, anisotropic flight patterns, etc.). In addition, fluctuations in the size of storms ("breathing" of the wind radii) in concurrent analyses have been noted by Moyer et al. (2007) due to the difficulties that wind scatterometers have in penetrating deep layers of precipitating clouds.

Thirty-six $\mathrm{H}^{*}$ Wind gridded wind fields for Hurricane Gustav, spanning 1330 UTC 28 August to 0130 UTC 2 September 2008, were interpolated every 15 min using a Lagrangian interpolation technique to construct the wind forcing for the ADCIRC model. The pressure fields were interpolated from the best-track data to the times when the $\mathrm{H}^{*}$ Wind analyses are available. A Holland model pressure profile was used to generate the pressure fields at model grid points at the same time interval as the wind speeds. The B parameter was specified using a regression curve fit from Vickery et al. (2000). No background far-field winds were added beyond the $8^{\circ} \times 8^{\circ} \mathrm{H}^{*}$ Wind grid domain.

\section{e. NAM model}

Analyses from the National Centers for Environmental Prediction (NCEP) NAM model grid 218 (12-km resolution on a Lambert conformal projection), containing wind components and pressure from 1200 UTC 28 August to 1800 UTC 2 September at 6-h frequency, were processed to create input wind and pressure fields for the ADCIRC grid. The NAM is based on the Nonhydrostatic Mesoscale Model (NMM) core of the Weather Research and Forecasting (WRF) model (Janjić et al. 2010). This is the same NMM dynamic core that is used in the Hurricane WRF (HWRF) model (Gopalakrishnan et al. 2010); however, no hurricane-specific initialization (vortex removal, bogus vortex insertion, vortex relocation), physics (drag saturation at high wind speeds, sea salt spray parameterization, flux coupling to an ocean model), or moving-nest vortex-tracking techniques are employed in the NAM.

\section{f. Track comparison}

The tracks corresponding to the different types of wind forcing are shown in Fig. 14. As the storm approaches the coastline, the $\mathrm{H}^{*}$ Wind track is quite close to the best track but it later shifts farther to the west, while the NAM track drifts well to the east of the best track prior to landfall. 


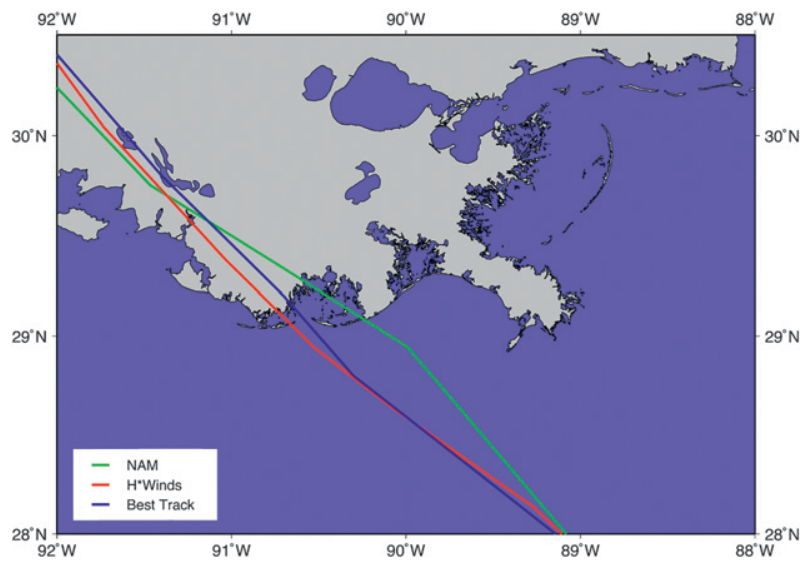

FIG. 14. Comparison of the storm tracks for the NAM model winds (green line), $\mathrm{H}^{*}$ Wind analyses (red line), and best-track data (blue line).

\section{g. Maximum elevation from $A W M, H^{*}$ Wind, and $N A M$ wind forcing}

A comparison among the maximum elevations produced by the AWM, H*Wind analyses, and NAM model forcings is shown in Fig. 15. The NAM winds are weakest and produce the lowest maximum elevation, $2.72 \mathrm{~m}$ near Port Sulphur. The areal extent of the surge is extremely limited. The $\mathrm{H}^{*}$ Wind analyses produce elevations of $3.23 \mathrm{~m}$ in magnitude near Tropical Bend. The AWM generates maximum elevations that surpass $4.91 \mathrm{~m}$ at English Turn.

An example of the wind distributions, in this case $1 \mathrm{~h}$ prior to landfall, is shown in Fig. 16. Although the NAM model has the most sophisticated numerics and physics of the three wind generation systems, it does not resolve the inner-core structure or gradients of the hurricane and it substantially underpredicts the strength of the winds throughout the grid domain. The maximum 10-min, 10-m wind speeds in the $\mathrm{H}^{*}$ Wind gridded wind analyses are $50 \%$ stronger $\left(36 \mathrm{~m} \mathrm{~s}^{-1}\right)$ than the NAM winds $\left(24 \mathrm{~m} \mathrm{~s}^{-1}\right)$. The AWM model produces the strongest winds $\left(42 \mathrm{~m} \mathrm{~s}^{-1}\right)$. In general, the central pressure, maximum sustained wind speed, and, especially, the wind radii diagnosed by the $\mathrm{H}^{*}$ Wind system can be quite different from those in the NHC forecast advisories and best-track files. However, in this instance, the central pressure and wind radii for the $\mathrm{H}^{*} \mathrm{Wind}$ and $\mathrm{AWM}$ wind fields are nearly identical. The major difference between the two products is due to the analyzed maximum 1-min sustained wind speeds of $41 \mathrm{~m} \mathrm{~s}^{-1}$ in the $\mathrm{H}^{*}$ Wind analysis versus $47 \mathrm{~m} \mathrm{~s}^{-1}$ in the NHC best-track input data used to construct the AWM wind distribution. This causes much higher winds at the radius of maximum winds in the AWM forcing, a closed $30 \mathrm{~m} \mathrm{~s}^{-1}$ isotach surrounding the storm, and stronger winds that blow

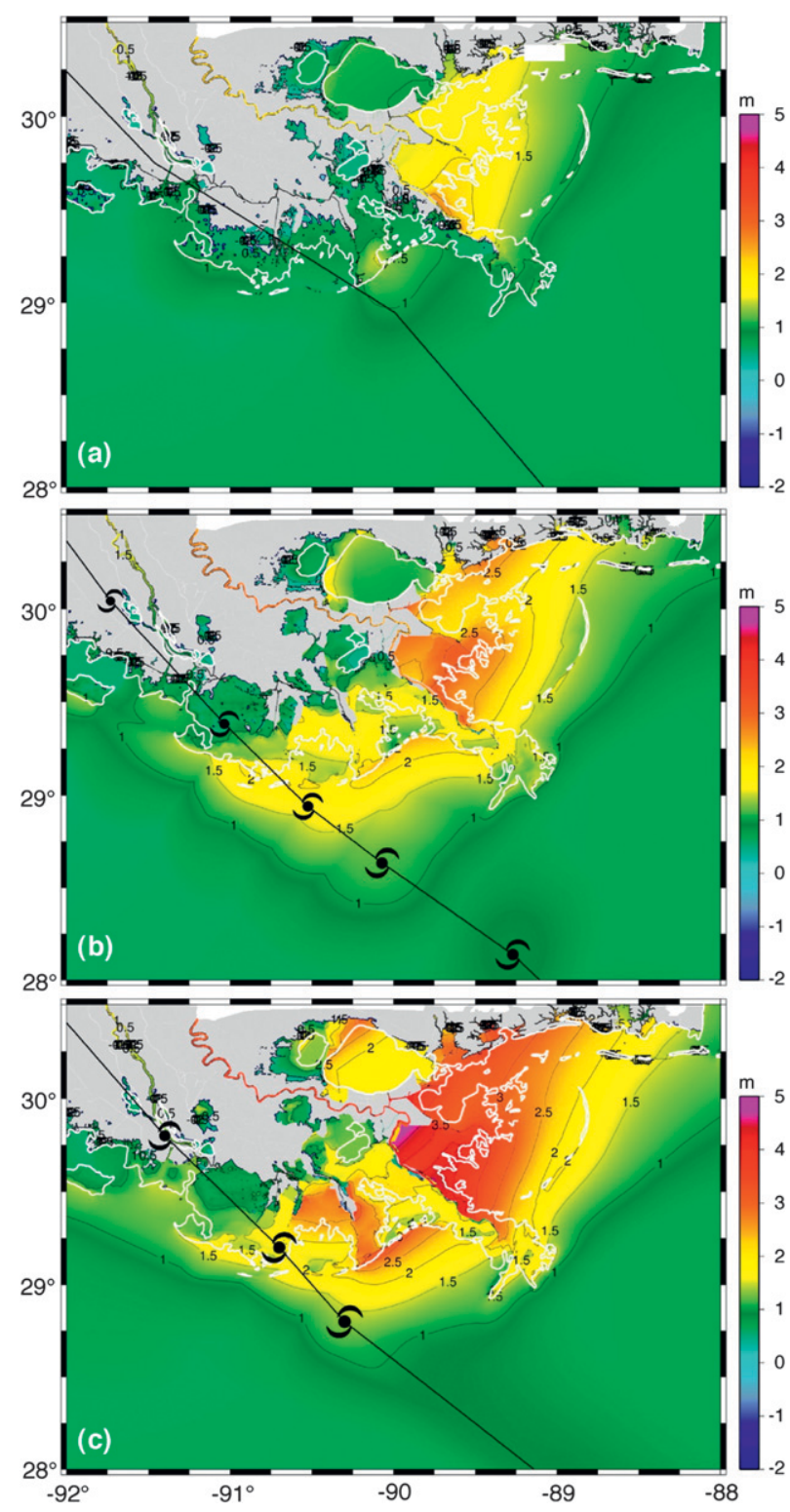

FIG. 15. Comparison of the maximum water surface elevation (m) relative to NAVD88 produced by wind forcing from the (a) NAM model, (b) $\mathrm{H}^{*}$ Wind analyses, and (c) an asymmetric wind model.

east-to-west across Lake Pontchartrain. Since the AWM produces an idealized representation of a hurricane, its winds are smooth and contain less structure than the $\mathrm{H}^{*}$ Wind analyses of observed measurements from multiple data sources.

\section{Comparison with observations}

\section{a. Station locations}

Time series of model elevations at gauge site locations were constructed to compare simulation results against 


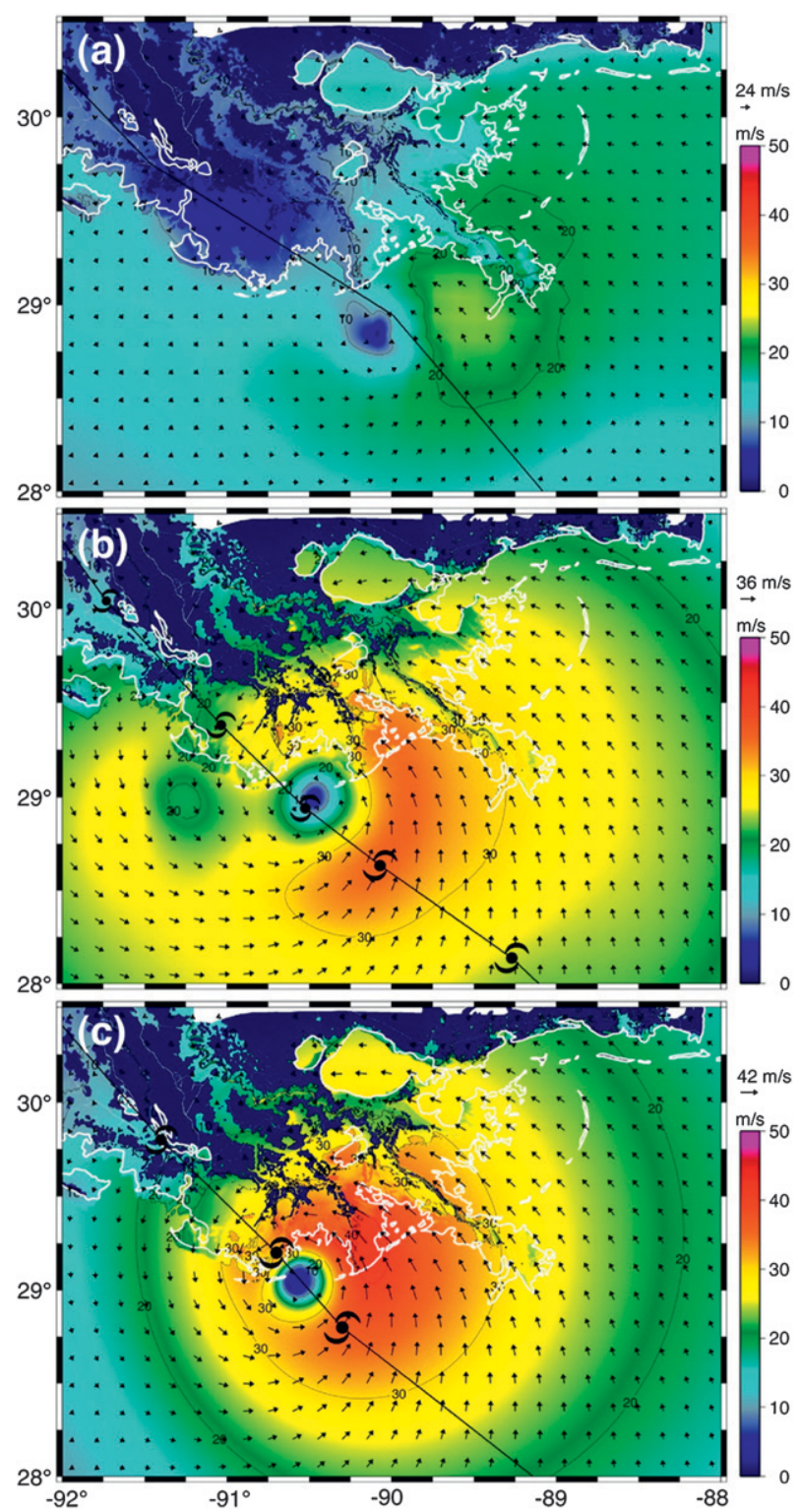

FIG. 16. Comparison of the wind speed $\left(\mathrm{m} \mathrm{s}^{-1}\right)$ (shaded colors) and wind direction (vectors) from the (a) NAM model, (b) $\mathrm{H}^{*}$ Wind analyses, and (c) an asymmetric wind model valid at 1400 UTC (0900 CDT), 1 h prior to Hurricane Gustav landfall on 1 Sep 2008.

recorded observations. The 52 model verification stations are composed of 13 NOAA, 9 U.S. Army Corps of Engineers (USACE), and 9 U.S. Geological Survey (USGS) permanent gauges and 21 temporary gauges (McGee et al. 2008) (Table 4, Fig. 17). The observed and modeled data were only sufficient at 40 of these 52 stations for use in the final skill assessment (Table 4). The 12 stations that were not used in the comparisons either had void/incomplete data records, erroneous observations, or the model lacked grid resolution (dry nodes) at these station locations so comparisons and statistical calculations could not be performed.

\section{b. Water surface elevations}

Figures $18 \mathrm{a}-\mathrm{u}$ show time series of water surface elevation at several of the stations listed in Table 4. They are grouped according to their distinct responses to Hurricane Gustav. Prestorm observed water levels are used to adjust the modeled water levels to account for local vertical datum offsets and subsidence at local stations (Westerink et al. 2008). Observed data at NOAA stations are referenced to the tidal MSL datum, while USGS and USACE stations are referenced to the geodetic NAVD88 datum.

\section{1) InNer Harbor Navigational CANAL RESPONSE}

Figures $18 \mathrm{a}-\mathrm{c}$ display the response of the water surface elevation to Hurricane Gustav at the Inner Harbor Navigational Canal (IHNC). Model elevations are greater than $3.70 \mathrm{~m}$ at all stations, reaching $4.08 \mathrm{~m}$ in the southern part of the canal when the AWM forcing is applied. In contrast, the $\mathrm{H}^{*}$ Wind forcing produces a maximum elevation of 2.46-2.75 m, while the NAM winds generate maximum elevations lower in magnitude, approximately 1.44-1.65 m.

The AWM maximum elevation is generally higher than, and peaks slightly earlier than, the observations. The AWM maximum elevation produced at station SSS-LA-ORL-009 is higher $(3.70 \mathrm{~m})$ than the observed value $(3.10 \mathrm{~m})$, while the SSS-LA-ORL-008 maximum elevation is close $(3.86 \mathrm{~m})$ to that which was measured $(3.71 \mathrm{~m})$. A high-amplitude secondary peak is also simulated that matches the observations. The higher amplitudes occur slightly earlier in the model simulations than in the observations. The $\mathrm{H}^{*}$ Wind-forced elevations are below the observations but the maximum is better aligned in time. The observed maximum elevation at the IHNC station is slightly lower than the modeled AWM elevation. In general, there is good agreement between the observed and AWM-forced ADCIRC-simulated patterns of evolution of the elevation.

\section{2) South Lake Pontchartrain Response}

The time series of water elevation at stations along the south shore of Lake Pontchartrain, (Figs. 18d-g) exhibit a triple-pulsed surge regime, with the highest elevations occurring at the end of the simulation. The observed and modeled maximum elevations produced by AWM forcing are in general agreement, with values around 1.321.44 and $1.57-1.68 \mathrm{~m}$, respectively, while those produced by the $\mathrm{H}^{*}$ Wind and NAM wind forcing are approximately $0.49-0.81 \mathrm{~m}$ in magnitude. The first pulse appears 
TABLE 4. Latitudes, longitudes, names, and source of the stations where the model-data comparisons were conducted.

\begin{tabular}{|c|c|c|c|}
\hline No. & Lat $\left({ }^{\circ} \mathrm{N}\right)$ & Lon $\left({ }^{\circ} \mathrm{E}\right)$ & Station name \\
\hline 1 & 30.0260555 & -90.0720277 & USACE London Ave Canal 1 (85626) \\
\hline 2 & 29.9085 & -90.0834111 & USACE Harvey Lock at GIWW (76200) \\
\hline 3 & 30.36579720 & -90.09228880 & USACE Lake Pontchartrain at Mandeville (85575) \\
\hline 4 & 30.02216380 & -90.11564440 & USACE Lake Pontchartrain at West End (85625) \\
\hline 5 & 29.96648050 & -90.02675000 & USACE IHNC (76160) \\
\hline 6* & 29.91250000 & -90.27305556 & USACE Sellers Canal at Hwy. 90, LA (Pier 90) (82720) \\
\hline 7 & 29.84833333 & -90.05972222 & USACE Harvey Canal at Boomtown Casino, LA (76230) \\
\hline 8 & 29.66944440 & -90.11055556 & USACE Barataria Waterway at Lafitte, LA (82875) \\
\hline 9 & 29.34250000 & -90.24555556 & USACE Golden Meadow Floodgate, LA (South) (82260) \\
\hline 10 & 30.358611 & -90.125833 & USGS 073802330 (NWS) Lake Pontchartrain \\
\hline 11 & 30.141667 & -89.863889 & USGS 300830089515000 Little Irish Bayou \\
\hline $12 *$ & 29.601 & -89.910222 & USGS 07380241 Suzie Bayou at Lake Hermitage Rd. \\
\hline $13^{*}$ & 29.272833 & -89.946806 & USGS 073802516 Barataria Pass at Grand Isle \\
\hline 14 & 29.58575 & -89.605972 & USGS 07374527 Northeast Bay Gardene \\
\hline $15^{*}$ & 29.856667 & -89.905833 & USGS 295124089542100 Caernarvon \\
\hline $16^{*}$ & 30.004139 & -89.938667 & USGS 073802338 IWW at I-510 bridge \\
\hline $17^{*}$ & 29.466667 & -90.1 & USGS 292800090060000 Little Lake near Bayou \\
\hline $18^{*}$ & 30.122778 & -89.250278 & USGS 3007220891501 Mississippi Sound \\
\hline 19 & 28.931666 & -89.406666 & NOAA 8760922 Pilots Station East, SW Pass \\
\hline 20 & 29.263333 & -89.956666 & NOAA 8761724 Grand Isle \\
\hline 21 & 29.115 & -90.200000 & NOAA 8762075 Port Fourchon \\
\hline 22 & 29.776666 & -90.418333 & NOAA 8762482 West Bank 1, Bayou Gauche \\
\hline 23 & 29.666666 & -91.236666 & NOAA 8764044 Tesoro Marine Terminal \\
\hline 24 & 29.868333 & -89.673333 & NOAA 8761305 Shell Beach \\
\hline 25 & 30.026666 & -90.113333 & NOAA 8761927 New Canal Station \\
\hline 26 & 30.050000 & -90.368333 & NOAA 8762372 East Bank 1, Norco, Bayou La Branche \\
\hline 27 & 29.713333 & -91.880000 & NOAA 8765251 Cypremort Point \\
\hline 28 & 29.544999 & -92.305000 & NOAA 8766072 Freshwater Canal Locks \\
\hline 29 & 30.225000 & -93.221666 & NOAA 8767816 Lake Charles \\
\hline 30 & 29.765000 & -93.343333 & NOAA 8768094 Calcasieu Pass \\
\hline 31 & 29.450000 & -91.340000 & NOAA 8764227 LAWMA, Amerada Pass \\
\hline 32 & 30.02136 & -90.12379 & USGS SSS-LA-JEF-005 \\
\hline 33 & 30.02121 & -90.18043 & USGS SSS-LA-JEF-013 \\
\hline 34 & 29.24706 & -90.20988 & USGS SSS-LA-LAF-006 \\
\hline 35 & 29.18723 & -90.09022 & USGS SSS-LA-LAF-007 \\
\hline 36 & 29.93675 & -90.13543 & USGS SSS-LA-ORL-001 \\
\hline $37 *$ & 30.02807 & -90.12029 & USGS SSS-LA-ORL-002 \\
\hline 38 & 30.02589 & -90.08292 & USGS SSS-LA-ORL-005 \\
\hline 39 & 29.98061 & -90.02260 & USGS SSS-LA-ORL-008 \\
\hline 40 & 30.00439 & -90.02618 & USGS SSS-LA-ORL-009 \\
\hline 41 & 30.03182 & -90.03658 & USGS SSS-LA-ORL-010 \\
\hline $42 *$ & 29.98243 & -89.94561 & USGS SSS-LA-ORL-012 \\
\hline 43 & 30.00628 & -89.93957 & USGS SSS-LA-ORL-013 \\
\hline 44 & 30.07697 & -89.94317 & USGS SSS-LA-ORL-014 \\
\hline 45 & 29.86738 & -90.01072 & USGS SSS-LA-PLA-001 \\
\hline $46^{*}$ & 29.86309 & -89.90876 & USGS SSS-LA-PLA-004 \\
\hline $47 *$ & 29.93954 & -89.92856 & USGS SSS-LA-STB-002 \\
\hline 48 & 29.85498 & -89.67865 & USGS SSS-LA-STB-004 \\
\hline $49 *$ & 29.49858 & -90.68173 & USGS SSS-LA-TER-008 \\
\hline 50 & 29.33291 & -90.64293 & USGS SSS-LA-TER-010 \\
\hline 51 & 29.24594 & -90.66109 & USGS SSS-LA-TER-024 \\
\hline 52 & 29.37317 & -90.71300 & USGS SSS-LA-TER-025 \\
\hline
\end{tabular}

* No observations, incomplete data records, bad observations, or lack of grid resolution/dry nodes to perform statistics or comparisons.

when the winds blow from the northeast or east and pile up water on the west side of Lake Pontchartrain, creating a sharp elevation gradient from west to east. As the winds rotate clockwise from the east or southeast during the storm's passage, water is pushed toward the northwest side of the lake, and an evacuation of water occurs along the southern shore. Then, as the winds rotate further, the water starts piling up in the north-northwest 

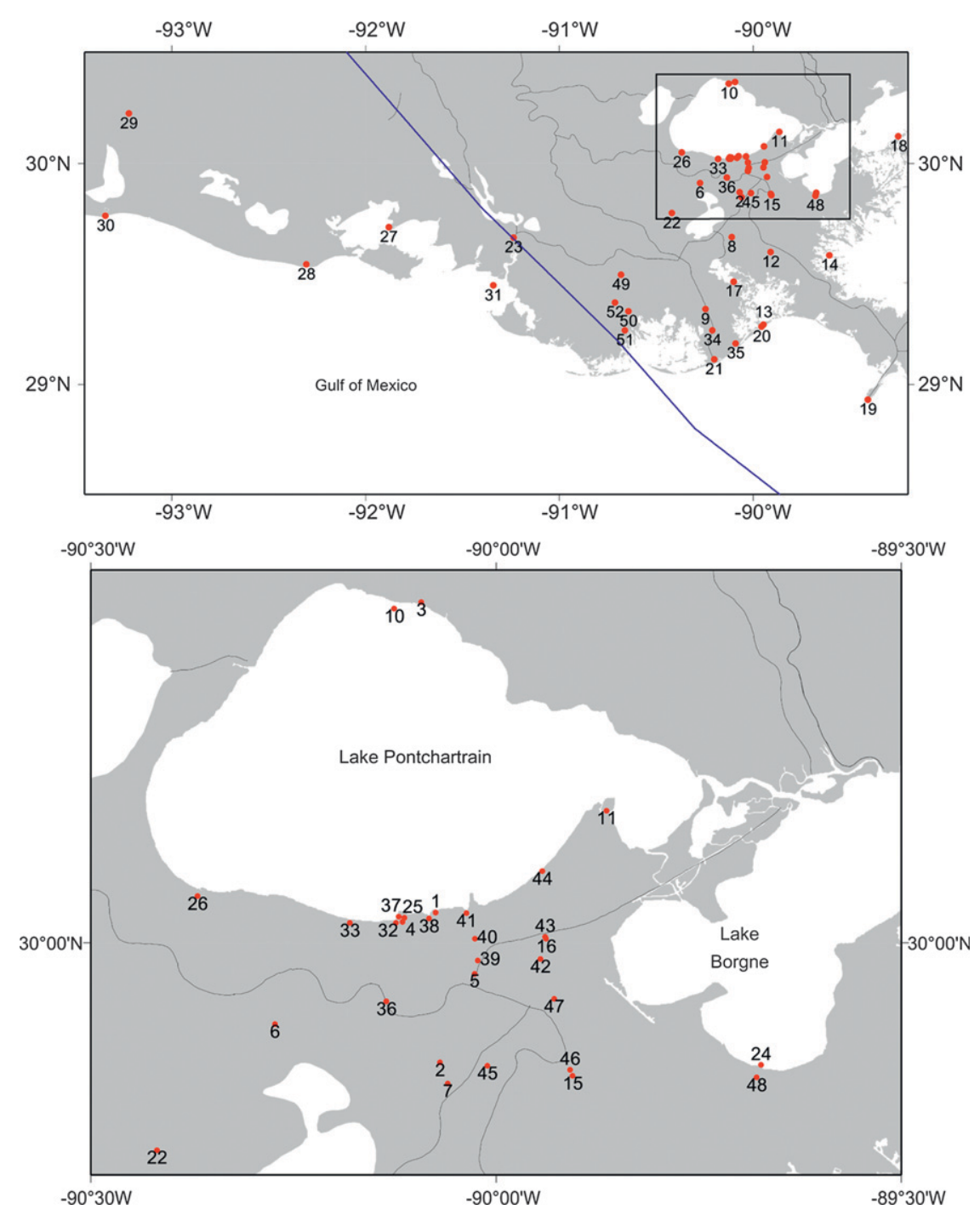

FIG. 17. Locations of the model verification stations. The numbers correspond to the stations in Table 4. The line indicates the location of the NHC best track for Hurricane Gustav.

side of the lake. Water from Lake Borgne is pushed through the Chef Menteur Pass and the Rigolets Strait into Lake Pontchartrain by the winds. This creates higher water elevations along the south shore of the lake, with water surface elevation differences larger than $3 \mathrm{~m}$ across these channels. As the winds turn toward the north-northwest, a sharp northwest-to-southeast gradient becomes noticeable and a drawdown is seen in the southern part of the lake. Later in the simulation, as the winds veer anticyclonically, begin blowing from the southsoutheast, and diminish in strength, the north-south elevation gradient relaxes, creating the highest elevations (larger than $1 \mathrm{~m}$ in amplitude) in the southern portions of the lake. The elevations produced by the $\mathrm{H}^{*}$ Wind forcing generally follow this trend during the earlier pulses, but tend to underpredict the surge at the end of the simulation. The NAM wind forcing also reproduces the general pattern but it underestimates the magnitudes of the water-level fluctuations. The $\mathrm{H}^{*}$ Wind- and NAM-forced model responses are directly related to the strength of the winds that blow across Lake Pontchartrain (see Fig. 16), which are smaller in magnitude than the AWM winds. This is consistent across the entire lake.

\section{3) North LAKe Pontchartrain RESPONSE}

The north Lake Pontchartrain station time series of elevations are displayed in Figs. 18h and 18i. They show a single surge that builds and persists throughout the simulation. The modeled elevations of $1.90-1.97 \mathrm{~m}$ forced by the AWM winds slightly overshoot the maximum observed water elevations of $1.52-1.89 \mathrm{~m}$, while the 
USGS SSS-LA-ORL-009
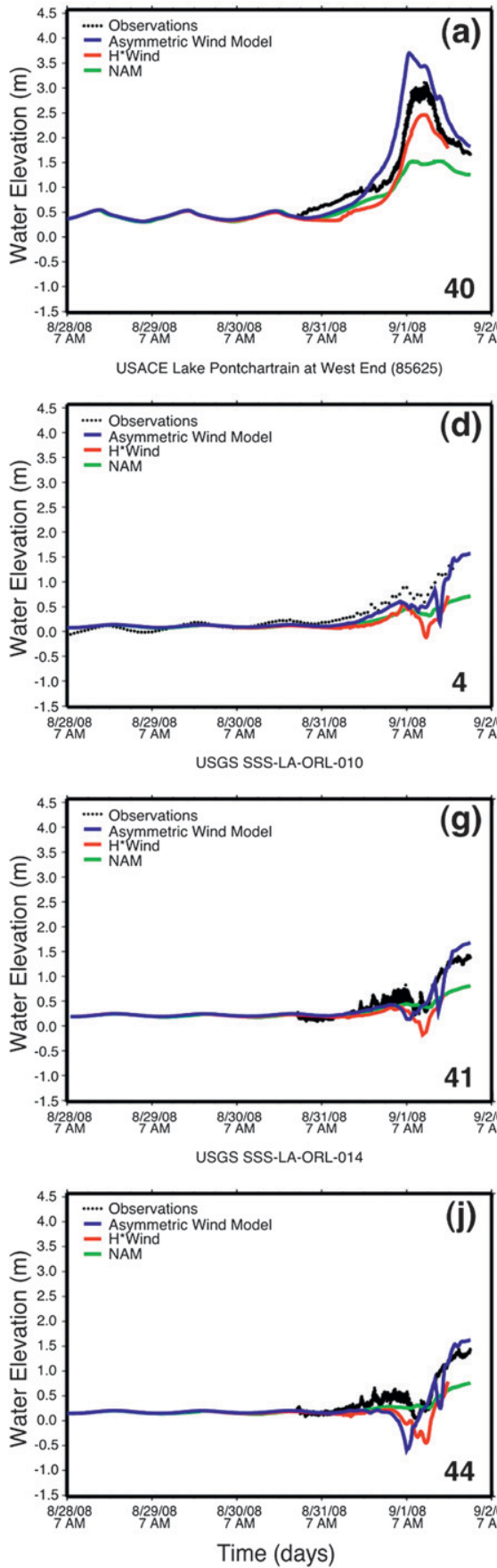

USGS SSS-LA-ORL-008

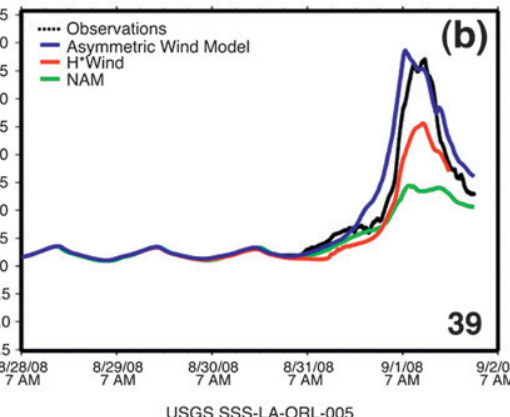

USACE Inner Harbor Navigational Canal (IHNC) (76160)

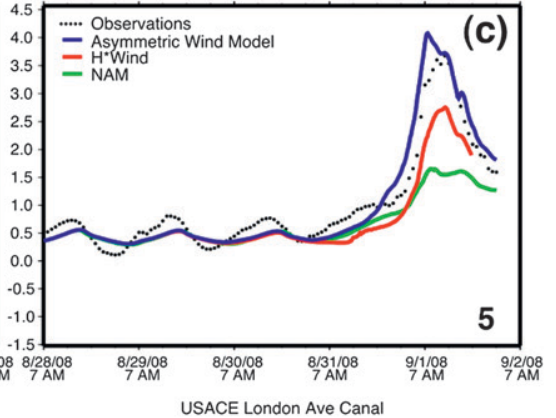

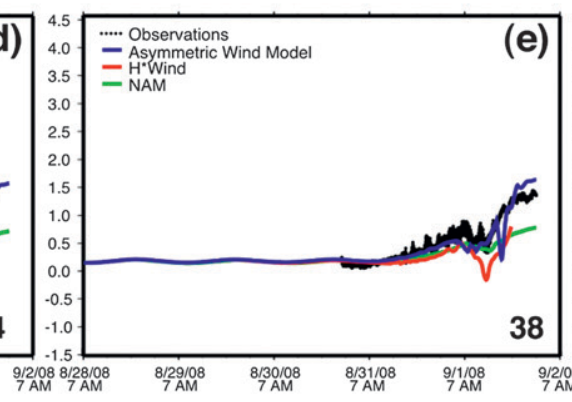

USGS 073802330 (NWS) Lake Pontchartrain

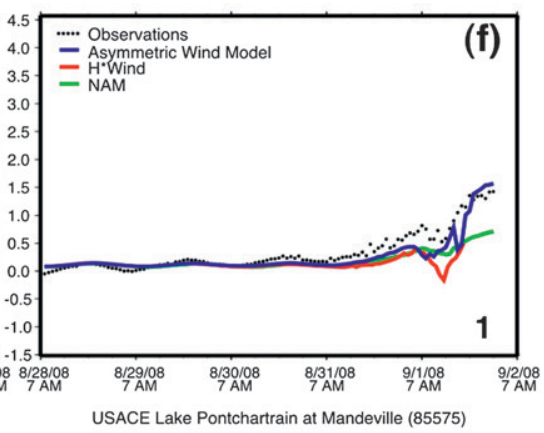

USACE Lake Pontchartrain at Mandeville (85575)
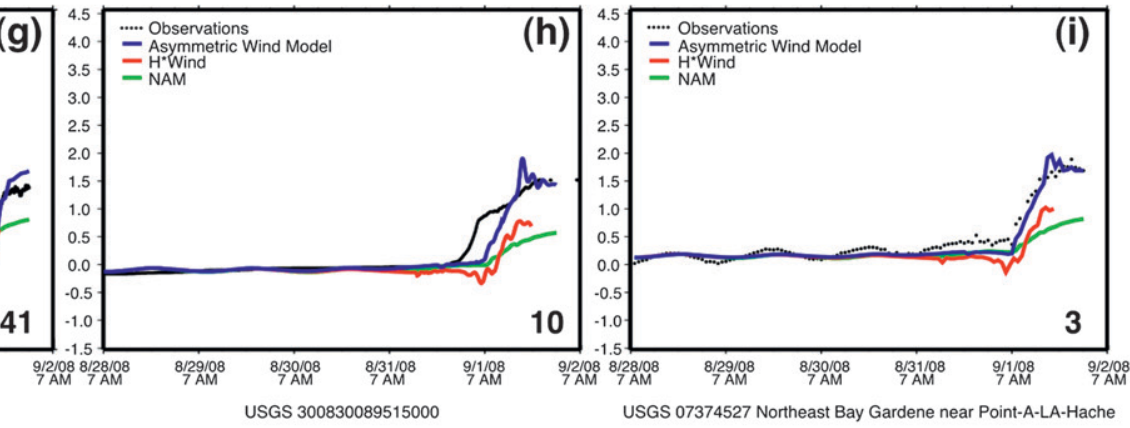

USGS 300830089515000

USGS 07374527 Northeast Bay Gardene near Point-A-LA-Hache
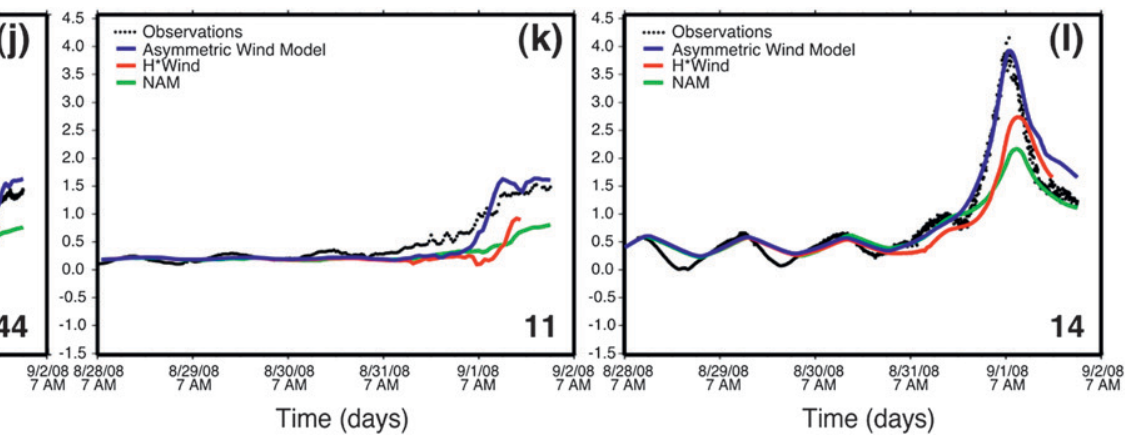

FIG. 18. Time series of observed (black dots) and simulated water surface elevations $(\mathrm{m})$ using asymmetric (blue lines), $\mathrm{H}^{*}$ Wind (red lines), and NAM (green lines) wind forcings at validation stations. NOAA stations are referenced to MSL, while USGS and USACE stations are referenced to the NAVD88 vertical datum. The number in the lower-right-hand corner in each panel corresponds to the stations in Table 4 and the map locations in Fig. 17.

$\mathrm{H}^{*}$ Wind and NAM winds are consistent with each other but considerably underpredict the surge by nearly half. At the USGS station to the west, values of $0.78 \mathrm{~m}$ with $\mathrm{H} *$ Wind forcing and $0.57 \mathrm{~m}$ with NAM wind forcing are reached. At the USACE station, farther to the east, elevations of $1.02 \mathrm{~m}\left(\mathrm{H}^{*}\right.$ Wind $)$ and $0.82 \mathrm{~m}(\mathrm{NAM})$ are simulated. The USACE station to the east shows slightly higher observed and modeled surge levels than the 
NOAA 8761305 Shell Beach, LA
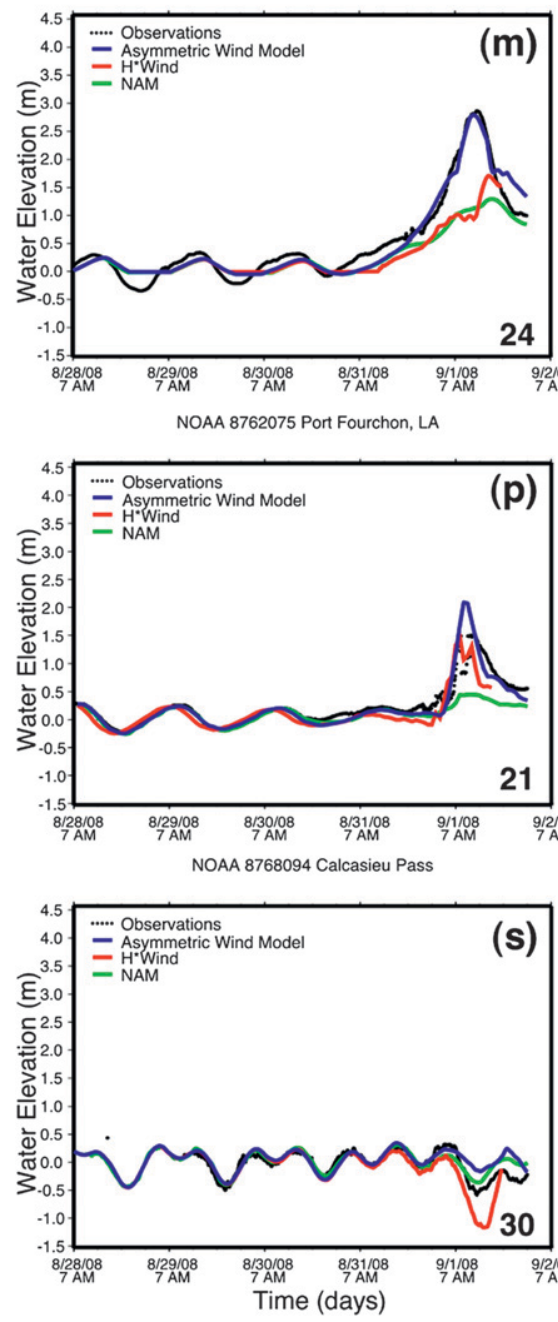

USGS SSS-LA-STB-004

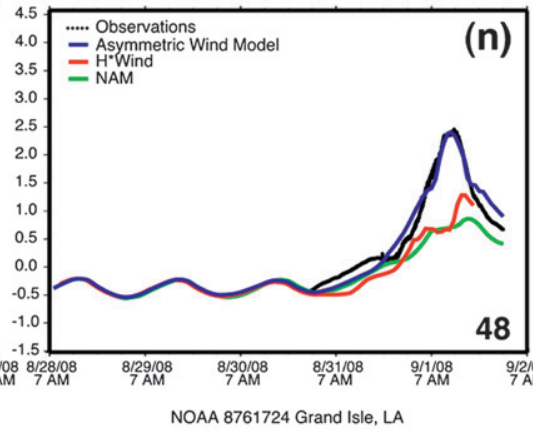

NOAA 8761724 Grand Isle, LA

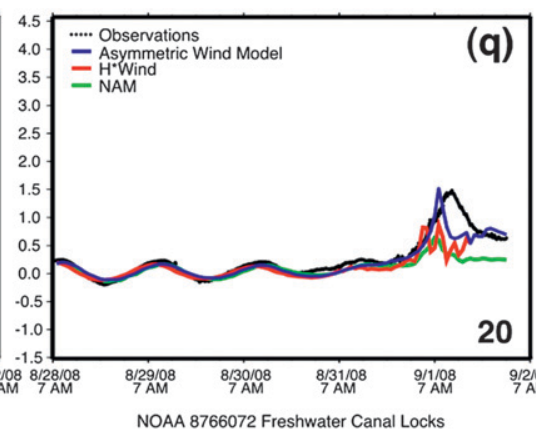

NOAA 8766072 Freshwater Canal Locks

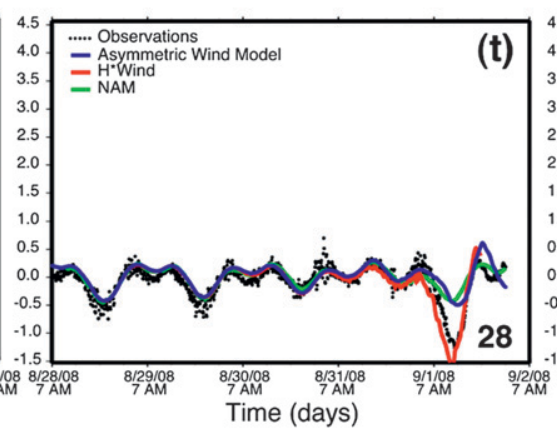

(t)

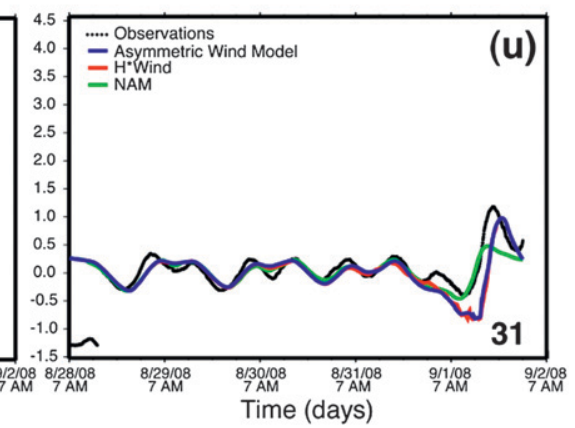

USACE Golden Meadow Floodgate, LA (South) (82260)
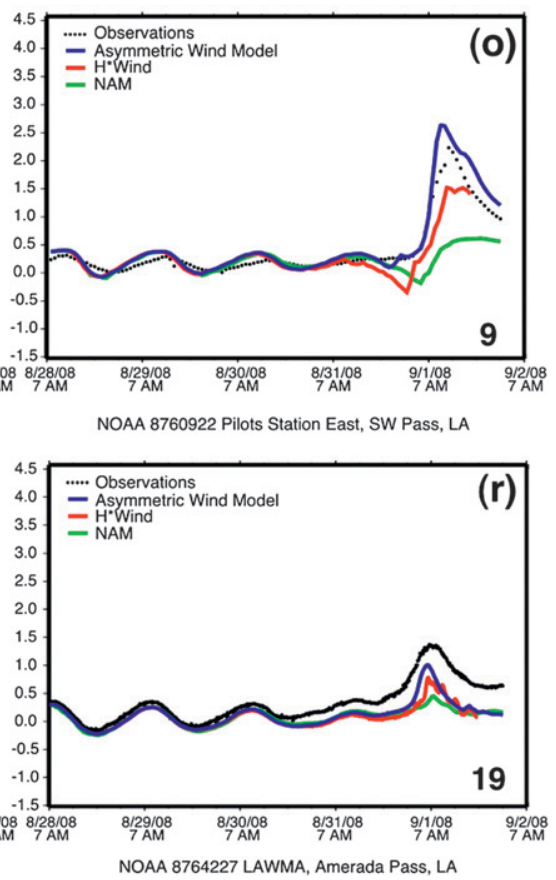

FIG. 18. (Continued)

USGS station to the west. At the USGS Lake Pontchartrain station, the buildup in the modeled water elevations is slightly delayed.

\section{4) EAst Lake Pontchartrain RESPONSE}

Figures $18 \mathrm{j}$ and $18 \mathrm{k}$ show time series of water elevations at two stations in the eastern portion of Lake Pontchartrain. Even though they are only $8 \mathrm{~km}$ apart, they exhibit two distinctly different storm surge regimes. The response of the station to the north (USGS300830089515000; see Fig. 18k) resembles that of the northern Lake Pontchartrain stations, with a single observed surge buildup of 1.52-1.63 m produced by AWM winds. On the other hand, the station to the south (SSSLA-ORL14; Fig. 18j) exhibits a triple pulse, as in the south Lake Pontchartrain regimes, with maximum observed elevations of 1.44 and $1.63 \mathrm{~m}$ forced by AWM winds. The distinct regimes are due to the evolution of the direction and magnitude of the winds with the passage of the hurricane with respect to the lake shoreline as explained in section $6 \mathrm{~b}(2)$. The $\mathrm{H}^{*}$ Wind and NAM wind-forced simulations tend to underestimate the water elevation. At the northern station, the maximum elevations reached 0.91 and $0.80 \mathrm{~m}$, respectively, and 0.78 and $0.75 \mathrm{~m}$ at the southern station.

\section{5) EAST OF THE MisSisSiPPI RIVER RESPONSE}

East of the Mississippi River, at Northeast Bay Gardene near Point-A-La-Hache, the tidal signal is evident and the water elevations are very high (Fig. 181), reaching observed amplitudes of 4.15 and $3.92 \mathrm{~m}$ with AWM forcing. Both the $\mathrm{H}^{*}$ Wind- and NAM-forced simulations underpredict the peak water elevation (2.73 and $2.16 \mathrm{~m}$, respectively). 


\section{6) LAKE Borgne AREA RESPONSE}

Figures $18 \mathrm{~m}$ and $18 \mathrm{n}$ show time series of water elevation at stations in the Lake Borgne area. Both stations exhibit a single surge response, with observed values ranging from 2.45 to $2.86 \mathrm{~m}$. An observed maximum elevation of $2.86 \mathrm{~m}$ occurs at the NOAA Shell Beach station, in good agreement with the AWM-forced ADCIRC-simulated value of $2.78 \mathrm{~m}$. The water elevation trace at temporary station SSS-LA-STB-004 reaches an observed maximum of $2.45 \mathrm{~m}$ and an AWM-forced maximum of $2.40 \mathrm{~m}$. Both the $\mathrm{H}^{*}$ Wind- and NAM-forced simulations underpredict the peak water level with values of 1.70 and $1.29 \mathrm{~m}$ for Shell Beach, respectively, and 1.28 and $0.86 \mathrm{~m}$ for SSSLA-STB-004. The modeled tidal signal is evident at both stations.

\section{7) Gulf of MeXico EAST OF THE STORM RESPONSE}

Figures $180-r$ show water elevation time series at stations in the Gulf of Mexico to the east of the storm. All stations exhibit prominent tidal signals and a single surge pulse ranging from 1.37 to $2.23 \mathrm{~m}$ in amplitude. The closer to the storm track, the higher the surge (2.23 m; Fig. 18o), which gradually diminishes toward the east (1.37 m; Fig. 18r). The AWM-forced simulations tend to overestimate the maximum water elevation close to the storm ( $2.63 \mathrm{~m}$; Fig. $18 \mathrm{o}$ ) but underpredict it far from the storm (1 m; Fig. 18r). Away from the storm, the AWM and $\mathrm{H}^{*}$ Wind- and NAM-forced simulations produce similar water elevations, though they are all smaller than observed $(1,0.77$, and $0.45 \mathrm{~m}$, respectively; Fig. 18r).

\section{8) Gulf of MeXico West of THE STORM RESPONSE}

Figures $18 \mathrm{~s}-\mathrm{u}$ show time series of water elevation at stations in the Gulf of Mexico to the west of the storm. A strong tidal signal dominates throughout most of the simulation. Toward the end of the simulation, a significant drawdown occurs at all stations. This is followed by a wraparound backside storm surge, particularly noticeable at Amerada Pass (Fig. 18u), which is close to the track of the storm. The resulting observed maximum elevation is $1.17 \mathrm{~m}$ and maximum elevations of $0.98,0.79$, and $0.47 \mathrm{~m}$ are reached with AWM, $\mathrm{H}^{*}$ Wind, and NAM wind forcings, respectively.

\section{c. Horizontal distribution of differences between observed and modeled maximum elevation}

The horizontal distribution of the differences between the observed and AWM-modeled maximum water elevations at the 40 stations where both observed and model

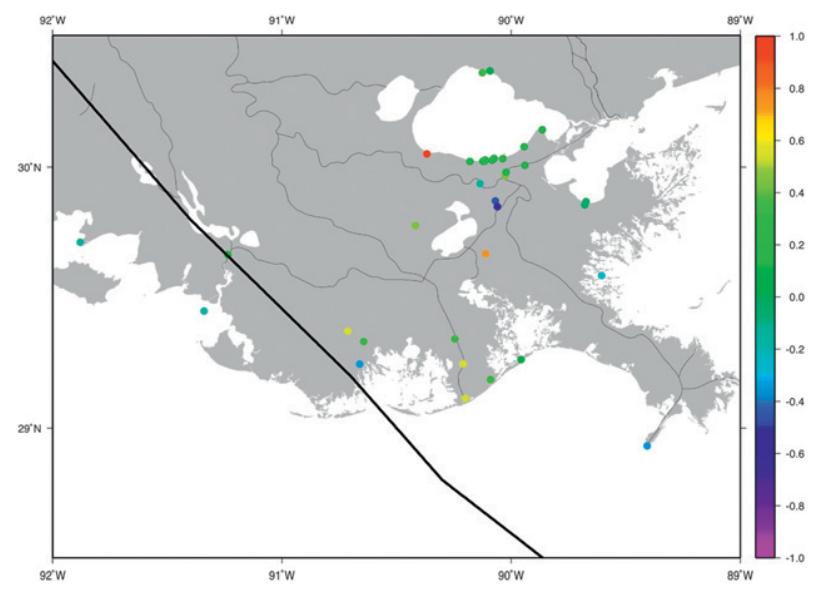

FIG. 19. Horizontal distribution of the differences between the modeled and observed maximum water surface elevations (m) using the wind forcing from AWM.

data were available (see Table 4) is shown in Fig. 19. In general, the differences are spatially consistent. The differences close to the track are slightly larger. There are two locations where the error is larger, which are probably attributable to inaccuracies in the grid.

\section{d. Dependence on wind forcing}

A scatterplot of predicted versus observed maximum water elevations at the 40 verification stations is displayed in Fig. 20 for the different types of wind forcing. In general, the AWM-forced simulation results fall within the $20 \%$ error cone. Maximum elevations from the $\mathrm{H}^{*}$ Windforced simulations are low, particularly at higher surges. NAM wind-forced ADCIRC simulations significantly underpredict the storm surge; amplitudes are typically $50 \%$ below the observed values.

A summary of the errors in the hindcast of the maximum elevation is shown in Table 5. The NAM winds produce a root-mean-square error (RMSE) in water elevation of $1.08 \mathrm{~m}$, while $\mathrm{H}^{*}$ Wind results in an RMSE of $0.69 \mathrm{~m}$. The AWM yields an RMSE of $0.36 \mathrm{~m}$.

Storm surge predictions are clearly sensitive to the characteristics of the wind forcing applied. The wind fields from the NAM, $\mathrm{H}^{*}$ Wind analysis, and AWM for Hurricane Gustav at $1 \mathrm{~h}$ before landfall are significantly different (Fig. 16). It is therefore not surprising that these three disparate atmospheric forcings produce different water surface elevation responses. The underprediction of maximum water surface elevation in the $\mathrm{H}^{*}$ Wind-forced simulations could be due to the exclusion of surface waves from the simulations. For Hurricane Katrina, additional surge due to wave setup was shown to be on the order of $0.10-0.3 \mathrm{~m}$ in sheltered areas (Dietrich et al. 2010). The NAM-forced water surface 


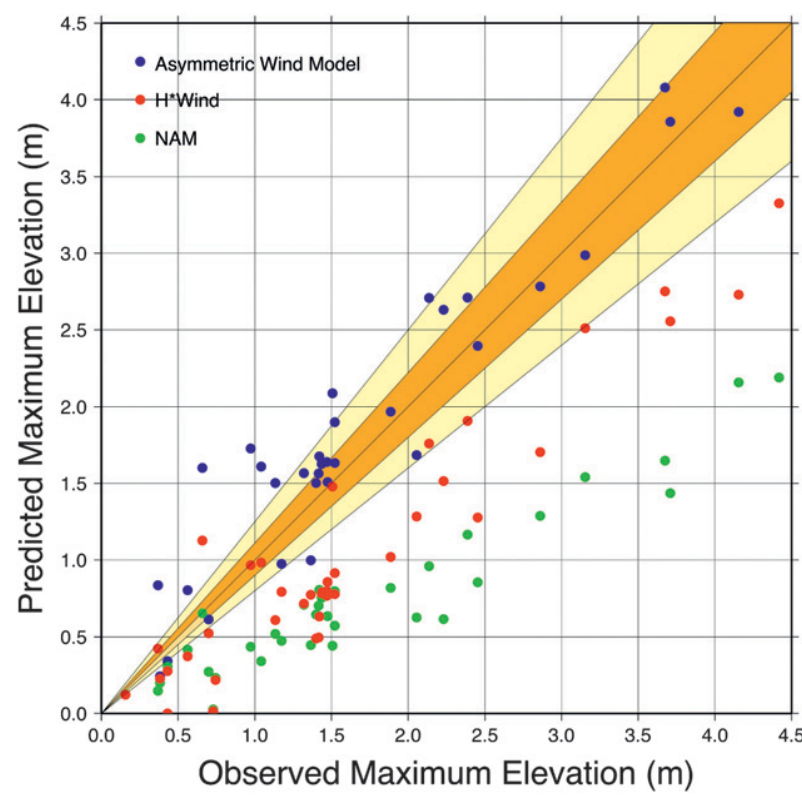

FIG. 20. Scatterplot of the predicted vs observed maximum water surface elevation (m) at verification stations. The 20\% (10\%) error cone is denoted by light yellow (dark orange) shading.

elevations are significantly underpredicted because the wind speed is underpredicted.

\section{e. Wind speed and direction}

Time series of 10-min, 10-m wind speed and direction at eight NOAA meteorological stations and their counterparts from the AWM, $\mathrm{H}^{*}$ Wind analyses, and the NAM model in Louisiana are presented in Figs. 21 and 22. In general, the NAM winds tend to follow the observations adequately during the earlier part of the simulations well before landfall, while the AWM starts generating winds $24-36 \mathrm{~h}$ prior to the passage of the storm (depending on $R_{\max }$ ) and $\mathrm{H}^{*}$ Wind analyses become available $12-24 \mathrm{~h}$ before landfall when the station falls into the $8^{\circ} \times 8^{\circ}$ area covered by the moving $\mathrm{H}^{*}$ Wind gridded analysis domain.

Wind speeds at stations along the Gulf of Mexico (Figs. 21a-d) show a decrease from stations east of the storm track (Figs. 21c and 21d) to stations west of the track (Figs. 21a and 21b). Observed wind speeds range from $13 \mathrm{~m} \mathrm{~s}^{-1}$ at Calcasieu Pass to $33 \mathrm{~m} \mathrm{~s}^{-1}$ at Pilots Station. The AWM reasonably captures the peaks at Calcasieu Pass and Amerada Pass, but overshoots those at Grand Isle and Pilots Station. The $\mathrm{H}^{*}$ Wind and NAM wind speeds at Pilots Station (Fig. 21d) exhibit the signature of an outer eye traversal, but the observations do not support this. At Grand Isle (Fig. 21c), the $\mathrm{H}^{*}$ Wind analysis reproduces the eye of the storm, which is partially captured by the observations, but overpredicts the
TABLE 5. RMSE in maximum water elevation produced by ADCIRC hindcasts driven with various types of wind forcing.

\begin{tabular}{llc}
\hline \hline Wind forcing & Horizontal resolution & $\begin{array}{c}\text { RMSE water } \\
\text { elevation }(\mathrm{m})\end{array}$ \\
\hline NAM & $12 \mathrm{~km}$ & 1.01 \\
H*Wind & $6 \mathrm{~km}$ & 0.69 \\
Asymmetric & ADCIRC grid & 0.36 \\
wind model & (down to $30 \mathrm{~m}$ in LA) & \\
\hline
\end{tabular}

maximum wind speed, while the NAM model underpredicts it. At Amerada Pass (Fig. 21b), west of the storm track, the $\mathrm{H}^{*}$ Wind and NAM wind traces suggest that the eye of the storm passed over the station, but this is not corroborated by the observations. At Calcasieu Pass (Fig. 21a), far to the west of the storm track, the NAM and observed wind speed time series are in close agreement, while the $\mathrm{H}^{*}$ Wind peak overshoots the observed maximum wind speed.

The wind speeds at stations in south Lake Pontchartrain are shown in Figs. 21e and 21f. The maximum wind speed at NOAA New Canal Station is $23 \mathrm{~m} \mathrm{~s}^{-1}$, while the predicted speeds from the AWM, $\mathrm{H}^{*}$ Wind, and NAM model are 27, 23, and $17 \mathrm{~m} \mathrm{~s}^{-1}$, respectively. The $\mathrm{H}^{*}$ Wind analysis reproduces the gradient of the winds best, while the AWM representation is a bit broad. The maximum wind speed observed at East Bank is $24 \mathrm{~m} \mathrm{~s}^{-1}$, while the predicted maximum wind speeds are lower for all wind forcings: AWM, $19 \mathrm{~m} \mathrm{~s}^{-1} ; \mathrm{H}^{*}$ Wind, $16 \mathrm{~m} \mathrm{~s}^{-1}$; and NAM winds, $12 \mathrm{~m} \mathrm{~s}^{-1}$.

The observed maximum wind speed inland, recorded at West Bank, is $21 \mathrm{~m} \mathrm{~s}^{-1}$ (Fig. 21g), while the maximum wind speed is overpredicted by the AWM $\left(31 \mathrm{~m} \mathrm{~s}^{-1}\right)$ and the $\mathrm{H}^{*}$ Wind analysis, $\left(27 \mathrm{~m} \mathrm{~s}^{-1}\right)$ but underpredicted by the NAM model $\left(14 \mathrm{~m} \mathrm{~s}^{-1}\right)$. At Shell Beach (Fig. 21h), the observed maximum wind speed of $24 \mathrm{~m} \mathrm{~s}^{-1}$ was well replicated by $\mathrm{H}^{*}$ Wind $\left(27 \mathrm{~m} \mathrm{~s}^{-1}\right)$, while the AWM winds were much stronger $\left(35 \mathrm{~m} \mathrm{~s}^{-1}\right)$, and the NAM peak winds were much weaker $\left(21 \mathrm{~m} \mathrm{~s}^{-1}\right)$.

Modeled wind directions are in reasonable agreement with the observations (Fig. 22). The $\mathrm{H}^{*}$ Wind analyses most faithfully replicate the observed wind directions, while there is a positive bias in the parameterized inflow angles in the AWM (which depend on the distance from the center of the storm) as the storm approaches the verification stations. This is particularly noticeable at stations to the west of the storm track, at Calcasieu Pass (Fig. 22a) and Amerada Pass (Fig. 22b). The NAM wind directions generally shift too gradually, consistent with the simulated weak openeyewall structure (Fig. 16a). In some cases, at Grand Isle (Fig. 22c) for example, the southerly wind shift is delayed by $4-6 \mathrm{~h}$. 


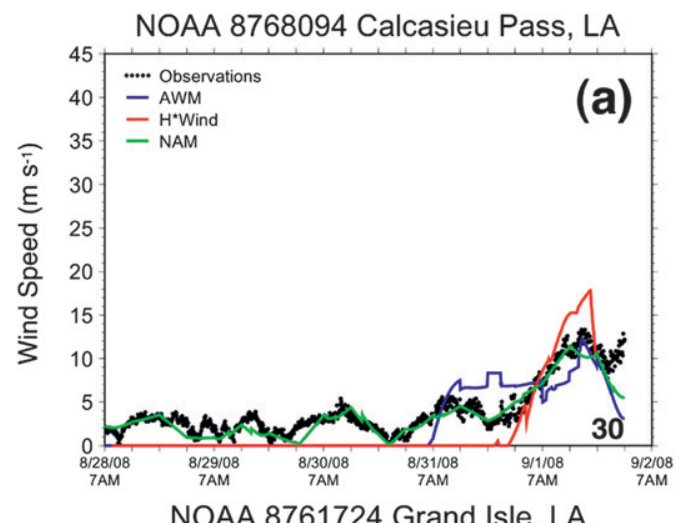

NOAA 8764227 LAWMA, Amerada Pass, LA

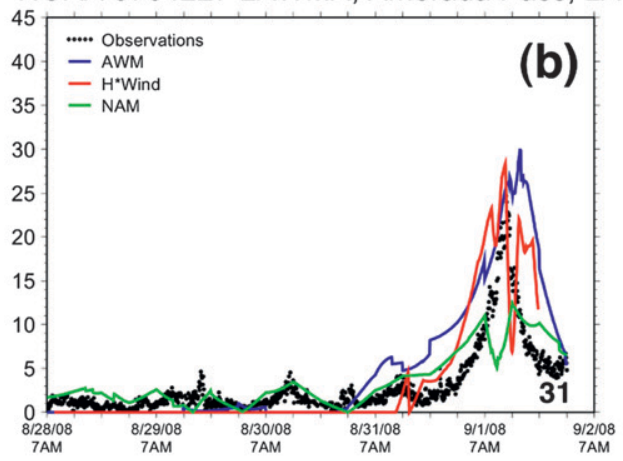

NOAA 8760922 Pilots Station East, LA
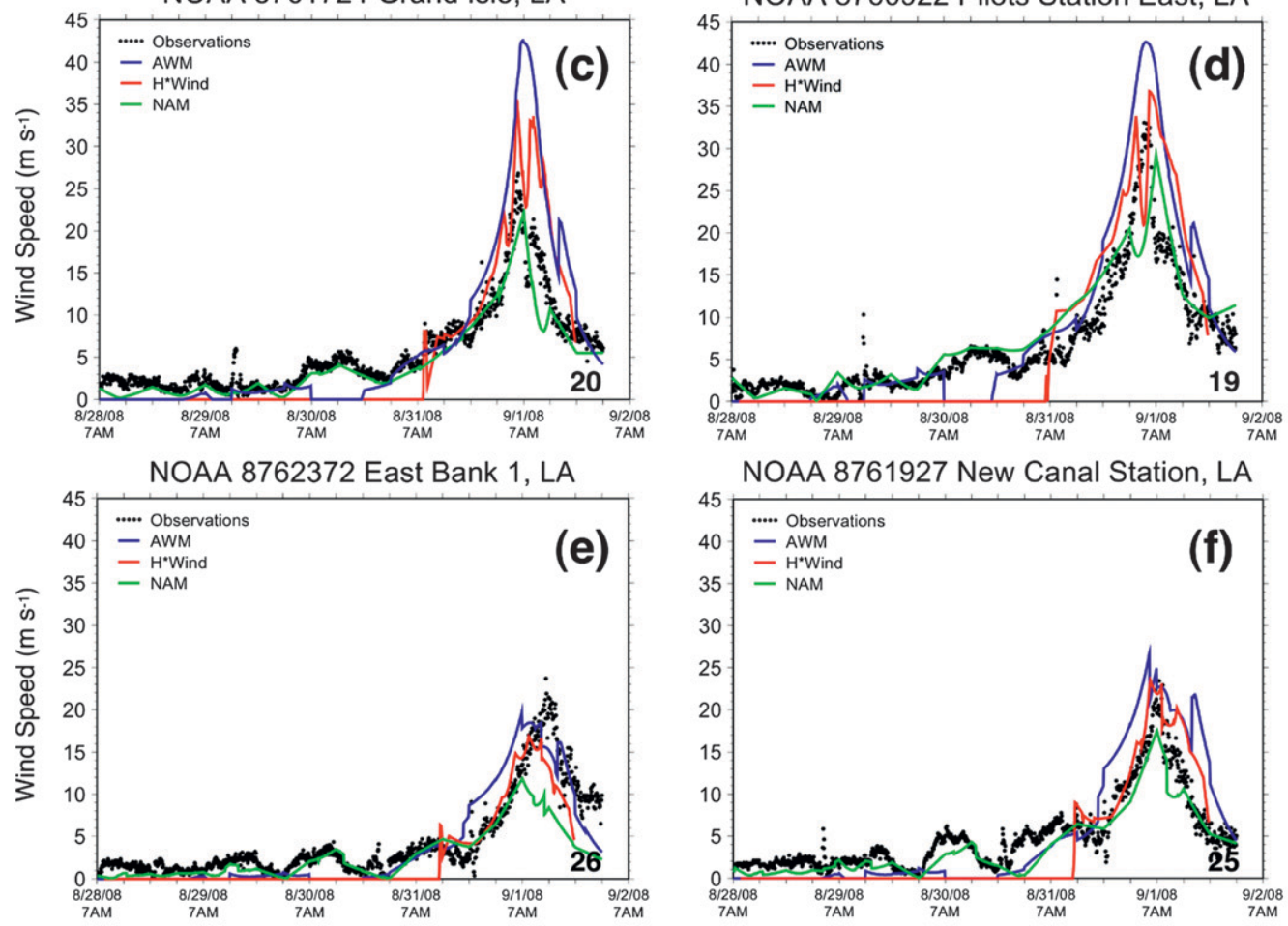

NOAA 8761927 New Canal Station, LA
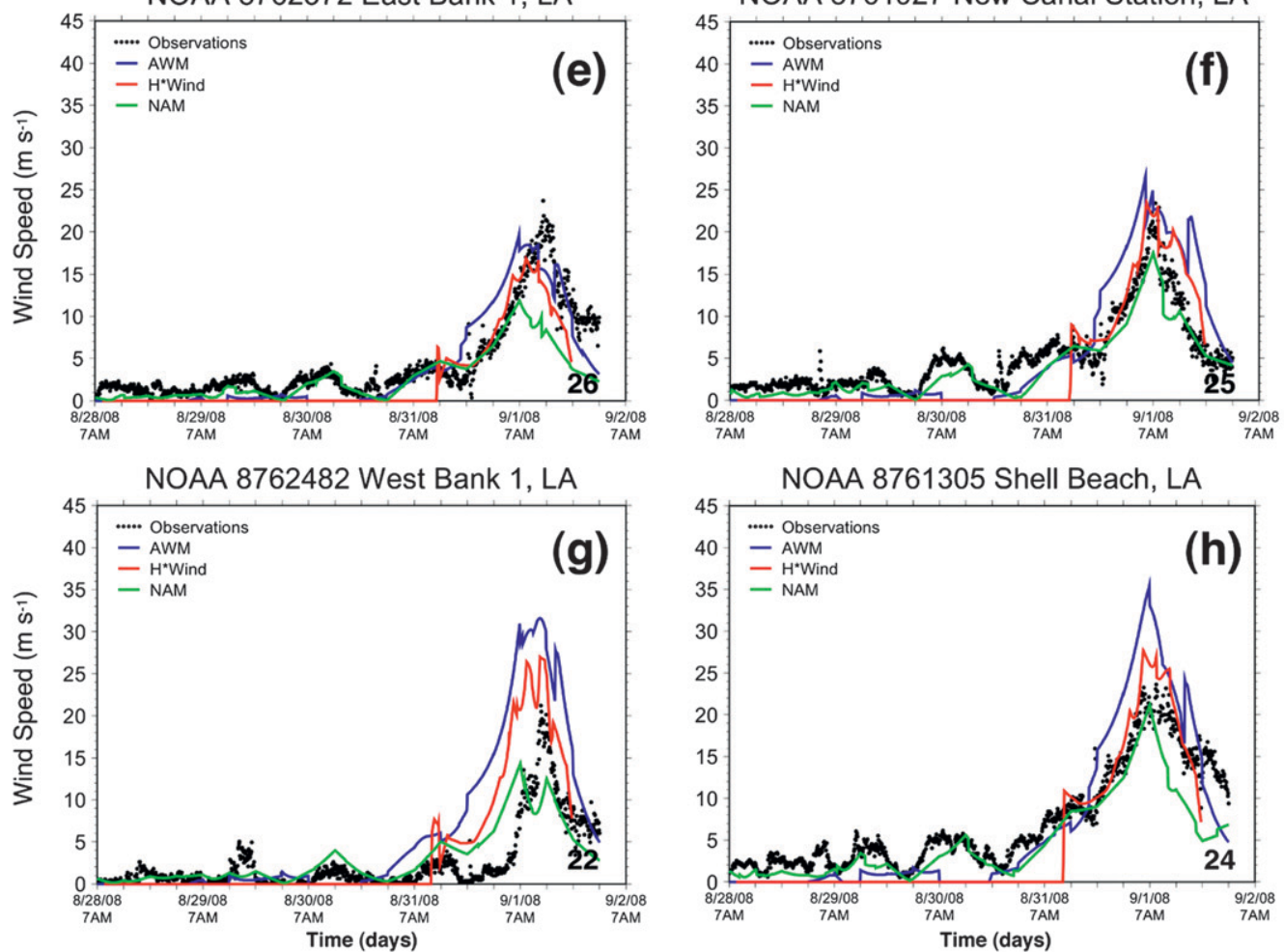

FIG. 21. Time series of wind speed $\left(\mathrm{m} \mathrm{s}^{-1}\right)$ at several NOAA meteorological stations (black dots) and the corresponding wind speeds produced by the asymmetric wind model (blue lines), $\mathrm{H}^{*} \mathrm{Wind}$ analyses (red lines), and NAM model (green lines) in LA during Hurricane Gustav. The number in the lower-right-hand corner in each panel corresponds to the stations in Table 4 and the map locations in Fig. 17. 
NOAA 8768094 Calcasieu Pass, LA NOAA 8764227 LAWMA, Amerada Pass, LA
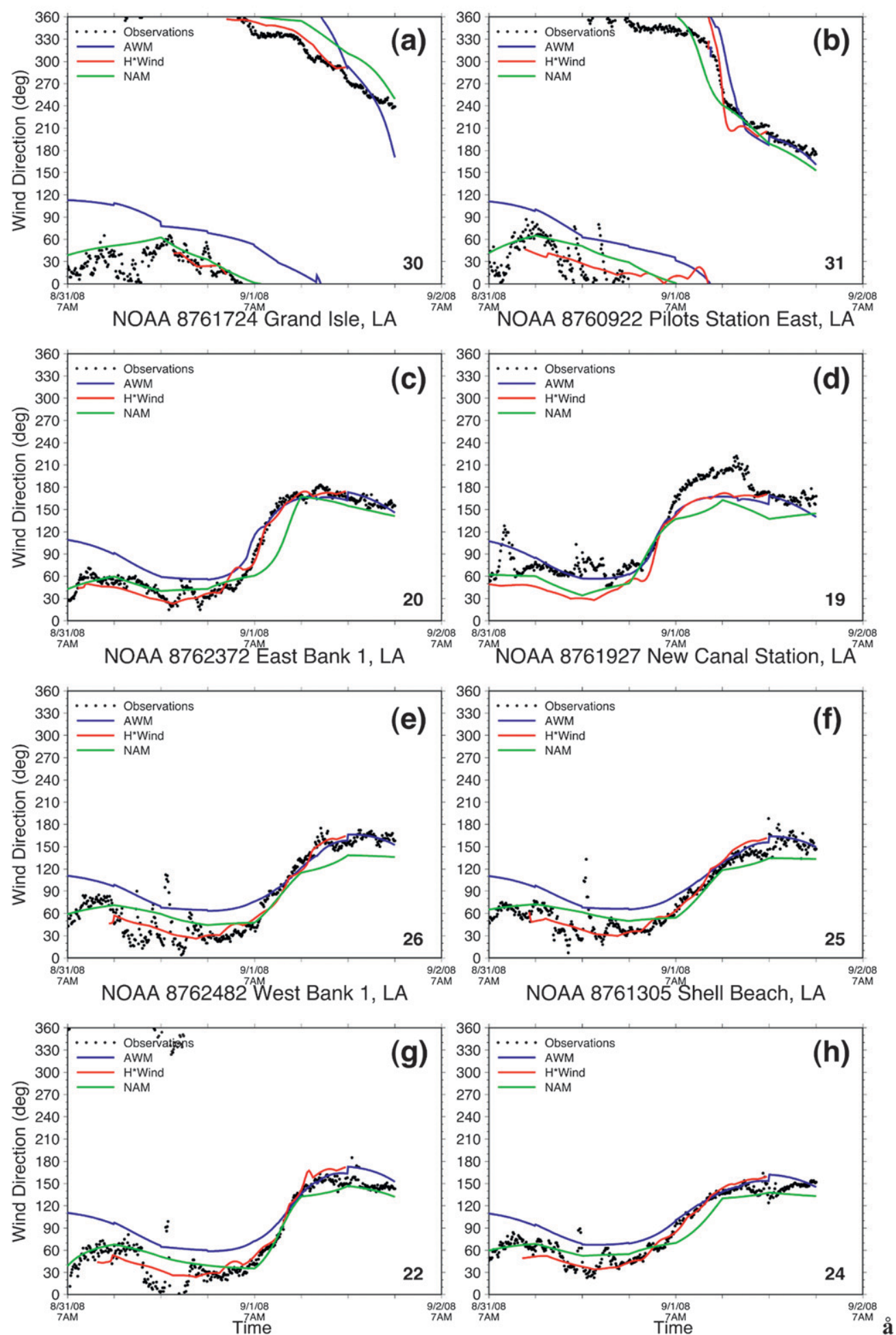

FIG. 22. Time series of wind directions $\left(\mathrm{m} \mathrm{s}^{-1}\right)$ at several NOAA meteorological stations (black dots) and the corresponding wind directions produced by the asymmetric wind model (blue lines), $\mathrm{H} * \mathrm{Wind}$ analyses (red lines), and NAM model (green lines) in LA approximately 1 day prior to the landfall of Hurricane Gustav. The number in the lower-right-hand corner in each panel corresponds to the stations in Table 4 and the map locations in Fig. 17. 
In summary, the AWM generates an idealized wind field based on NHC storm track parameters and seems to reproduce the hurricane's signal reasonably well albeit with a tendency to overpredict the maximum wind speed and to underestimate the cross-isobaric frictional inflow angle far from the center of the storm. While $\mathrm{H}^{*}$ Winds are typically more accurate than the AWM, they are only available on an $8^{\circ} \times 8^{\circ}$ grid. This limits their availability at the coast to about 1 day prior to landfall. Being observationally based, $\mathrm{H}^{*}$ Wind is not available as a forecast product. The NAM winds follow the observed signal far ahead of the storm but tend to underpredict the storm's peak wind speeds, which is consistent with the known limitations of the model.

\section{Summary and conclusions}

In the years since Hurricane Katrina (2005), considerable effort has been invested into improving our ability to model coastal storm surge. Substantially greater computational requirements have accompanied the advancement in modeling capability. Typically, real-time forecasting applications have strict model execution time constraints and, therefore, have tended to favor simpler model implementations (e.g., coarse grid resolution) that are able to run quickly. With the increased availability of high-performance computing systems comprising thousands of compute cores, it is becoming possible to expeditiously run 3-5-day storm surge forecasts using a computationally intensive modeling system. The answer to the question of whether the additional computational effort is worthwhile, given the expected error in storm surge due to the inaccuracies in the tropical cyclone forecasts, is now within our grasp.

The evolution and convergence of modeled storm surge forecasts were examined using a high-resolution implementation of the ADCIRC coastal circulation and surge model. ADCIRC was forced using an asymmetric gradient wind model (AWM) that ingested NHC storm parameters for the final 20 meteorological forecasts (covering the final 5 days) for Hurricane Gustav (2008). Hindcast simulations were also performed with ADCIRC using the AWM with the best track, $\mathrm{H}^{*}$ Wind, and the NAM and compared to observational data to establish the basic model skill.

Coupled directly to the ADCIRC coastal ocean model, the AWM can be used to generate hurricane wind distributions quickly, thereby maximizing the number of hours of forecast utility for operational storm surge prediction. The AWM model is sophisticated enough to produce a fairly realistic rendition of winds and storm surge, provided the NHC storm track parameters are reasonably accurate. When compared against meteorological measurements from NOAA and USGS stations, the AWM peak wind speeds tended to overpredict the observations close to the storm, but were quite reasonable over much of the storm's area of influence. In general, the AWM produced winds speeds stronger than $\mathrm{H}^{*}$ Wind, while both the AWM and $\mathrm{H}^{*}$ Wind winds were significantly stronger than NAM. The $\mathrm{H}^{*}$ Wind system ingests all available meteorological observations to produce composite products; therefore, the $\mathrm{H}^{*}$ Wind peak analyzed wind speeds at station locations are generally the closest to the anemometer measurements recorded by National Weather Service Forecast Offices. While extremely useful for hindcast studies, $\mathrm{H}^{*}$ Wind provides analyses, not forecasts; so, it is not useful for storm surge prediction. Even though the NAM has been used successfully to drive coastal ocean models, it is not designed to resolve tropical cyclones and its winds are too weak to generate realistic magnitudes of storm surge. Therefore, it is not the preferred wind product for hurricane-forced storm surge simulations.

Comparisons of model water levels against observations from NOAA, USGS, and USACE stations show that the AWM-forced ADCIRC model generates greater surge for Hurricane Gustav than $\mathrm{H}^{*}$ Wind and NAM wind forcing, which is consistent with higher AWM wind speeds. The AWM-forced ADCIRC model water levels best matched the observed maximum water levels at 40 stations in southern Louisiana, with an overall RMS error of $0.36 \mathrm{~m}$. To increase the execution speed for forecasting purposes, ADCIRC was run without coupling to a wave model, although it is well known that waves provide additional surge due to wave setup. For Hurricane Katrina, this additional surge has been shown to exceed $0.5 \mathrm{~m}$ in areas that were exposed to deep water waves such as along the lower Mississippi River Delta, but was typically in the range of $0.1-0.3 \mathrm{~m}$ in more sheltered areas such as Mississippi Sound, Breton Sound, and Lakes Borgne and Pontchartrain (Dietrich et al. 2010). A comparable contribution due to wave setup is reasonable for Hurricane Gustav, as well. Thus, the slight overprediction of wind speed by the AWM to some extent compensated for the lack of explicit inclusion of waves in the surge computations. Further evaluation of the AWM model on additional storms should provide a better understanding of its error characteristics.

Over the full 5 days of forecasts (NHC advisories 15-35) that were examined in this study, variability in the storm forecasts translated into surge variations of up to $4 \mathrm{~m}$ north and west of Terrebonne Bay and $2 \mathrm{~m}$ across much of the rest of the area. Throughout the entire region the RMS difference from the best-track hindcast exceeded $1 \mathrm{~m}$. This was associated with the 
generally west to east migration of the predicted storm track, as well as the variability in the other storm parameters. The storm surge variability remained relatively constant during the first half of the analysis period; thereafter, it dropped significantly and converged steadily. The final 10-12 advisories, encompassing the last 2.53 days of the storm's lifetime, provide a reasonable estimate of the final storm surge and inundation.

This study provides a detailed perspective, for this specific storm, of the variability in the storm surge due to variability in the meteorological forecast and how this changes as the storm approaches landfall. The conclusions of this analysis depend on both the quality of the meteorological forecasts and on the landfall location and therefore cannot be generalized to all storms in all locations. Nevertheless, this first attempt to translate variability in forecast meteorology into storm surge variability provides useful insights for guiding the potential use of storm surge models for forecast purposes.

Acknowledgments. This research was funded by National Science Foundation Grant DMS-0620791, NOAA IOOS Grant NA07NOS4730212, and the US Department of Homeland Security under Award 2008ST-061-ND 0001. The views and conclusions contained in this document are those of the authors and should not be interpreted as necessarily representing the official policies, either expressed or implied, of the U.S. Department of Homeland Security. Simulations were run on Louisiana State University's QueenBee and the University of North Carolina's Topsail supercomputing clusters.

\section{REFERENCES}

Berg, R., cited 2009: Tropical cyclone report Hurricane Ike (AL092008). National Hurricane Center. [Available online at http://www.nhc.noaa.gov/pdf/TCR-AL092008_Ike_3May10.pdf.]

Beven, J. L., and T. B. Kimberlain, cited 2009: Tropical cyclone report Hurricane Gustav (AL072008). National Hurricane Center. [Available online at http://www.nhc.noaa.gov/pdf/TCRAL072008_Gustav.pdf.]

Blain, C. A., and A. McManus, 1998: A real-time application of the ADCIRC-2DDI hydrodynamic model for JTFEX97 at Camp Pendleton, CA. NRL/FR/7322-98-9684, Naval Research Laboratory, Department of the Navy, $34 \mathrm{pp}$.

_ J. J. Westerink, and R. A. Luettich, 1994: The influence of domain size on the response characteristics of a hurricane storm surge model. J. Geophys. Res., 99 (C9), 18 467-18 479.

,$- \ldots$, and —_, 1998: Grid convergence studies for the prediction of hurricane storm surge. Int. J. Numer. Methods Fluids, 26, 369-401.

Blake, E. S., E. N. Rappaport, and C. W. Landsea, 2007: The deadliest, costliest, and most intense United States tropical cyclones from 1851 to 2006 (and other frequently requested hurricane facts). NOAA Tech. Memo. NWS TPC-5, NOAA/NWS/
Tropical Prediction Center/National Hurricane Center, Miami, FL, 43 pp.

Bunya, S., and Coauthors, 2010: A high-resolution coupled riverine flow, tide, wind, wind wave, and storm surge model for southern Louisiana and Mississippi. Part I: Model development and validation. Mon. Wea. Rev., 138, 345-377.

Dietrich, J. C., and Coauthors, 2010: A high-resolution coupled riverine flow, tide, wind, wind wave, and storm surge model for southern Louisiana and Mississippi. Part II: Synoptic description and analysis of Hurricanes Katrina and Rita. Mon. Wea. Rev., 138, 378-404.

Dietsche, D., S. Hagen, and P. Bacopoulos, 2007: Storm surge simulations for Hurricane Hugo (1989): On the significance of inundation areas. J. Waterw. Port Coastal Ocean Eng., 133, 183-191.

Doyle, T. W., C. P. O’Neil, M. P. V. Melder, A. S. From, and M. M. Palta, 2007: Tidal freshwater swamps of the southeastern United States: Effects of land use, hurricanes, sealevel rise, and climate change. Ecology of Tidal Freshwater Forested Wetlands of the Southeastern United States, W. H. Conner, T. W. Doyle, and K. W. Krauss, Eds., Springer, 1-28.

Ebersole, B. A., J. J. Westerink, D. T. Resio, and R. G. Dean, 2007: Performance evaluation of the New Orleans and Southeast Louisiana Hurricane Protection System. Volume IV-The storm. Final Report of the Interagency Performance Evaluation Task Force, U.S. Army Corps of Engineers, Washington, DC, 263 pp.

FEMA, 2008: Flood insurance study: Southeastern parishes, Louisiana, intermediate submission 2: Offshore water levels and waves. U.S. Army Corps of Engineers, New Orleans District, New Orleans, LA, 850 pp. [Available online at http://nd.edu/ $\sim$ coast/femaIDS2.html.]

Flather, R. A., and K. P. Hubbert, 1990: Tide and surge models for shallow water-Morecambe Bay revisited. Model. Mar. Syst., I, 135-166.

Fleming, J., C. Fulcher, R. Luettich, B. Estrade, G. Allen, and H. Winer, 2008: A real time storm surge forecasting system using ADCIRC. Estuarine and Coastal Modeling X, M. L. Spaulding, Ed., ASCE, 893-912.

Forbes, C., R. Luettich, and C. Mattocks, 2010: Storm surge simulations of Hurricane Ike: Its impact in Louisiana and Texas: Estuarine and Coastal Modeling XI, M. L. Spaulding, Ed., ASCE, 704-723.

Franklin, J. L., 2008: National Hurricane Center forecast verification. Preprints, 28th Conf. on Hurricanes and Tropical Meteorology, Orlando, FL, Amer. Meteor. Soc., 13A.1. [Available online at http://ams.confex.com/ams/pdfpapers/137870.pdf.]

Gopalakrishnan, S., Q. Liu, T. Marchok, D. Sheinin, N. Surgi, R. Tuleya, R. Yablonsky, and X. Zhang, cited 2010: Hurricane Weather Research and Forecasting (HWRF) model scientific documentation. NOAA/ESRL/Developmental Testbed Center. [Available online at http://www.dtcenter.org/HurrWRF/ users/docs/scientific_documents/HWRF_final_2-2_cm.pdf.]

Graber, H., V. Cardone, R. Jensen, D. Slinn, S. Hagen, A. Cox, M. Powell, and C. Grassl, 2006: Coastal forecasts and storm surge predictions for tropical cyclones: A timely partnership program. Oceanography, 19, 130-141.

Holland, G. J., 1980: An analytical model of the wind and pressure profiles in hurricanes. Mon. Wea. Rev., 108, 1212-1218.

Janjić, Z., R. Gall, and M. E. Pyle, 2010: Scientific documentation for the NMM solver. NCAR Tech. Note NCAR/TN- 477+STR, $54 \mathrm{pp}$.

Luettich, R. A., and J. J. Westerink, 2003: Combined discharge and radiation boundary condition in the ADCIRC hydrodynamic 
model: Theory and documentation. Contractors' Rep., U.S. Army Corps of Engineers New Orleans District, 16 pp. [Available from U.S. Army Corps of Engineers, New Orleans, ATTN: CEMVN-IM-SM Library, P.O. Box 60267, New Orleans, LA 70160-0267.]

, and _ 2006: Formulation and numerical implementations of the 2D/3D ADCIRC finite element model, version 44.XX. $74 \mathrm{pp}$. [Available online at http://adcirc.org/adcirc_theory_ 2004_12_08.pdf.]

, - — , and N. W. Sheffner, 1992: ADCIRC: An advanced three-dimensional circulation model for shelves, coasts and estuaries. Report 1: Theory and methodology of ADCIRC2DDI and ADCIRC-3DL. U.S. Army Corps of Engineers Tech Rep. DRP-92-6, 137 pp. [Available from ERDC Vicksburg (WES), U.S. Army Engineer Waterways Experiment Station (WES), ATTN: ERDC-ITL-L, 3909 Halls Ferry Rd., Vicksburg, MS 39180-6199.]

— J. Hudgins, and C. Goodall, 1996: Initial results from a combined tide and storm surge forecast model of the U.S. east coast, Gulf of Mexico and Caribbean Sea. Preprints, 15th Conf. on Weather Analysis and Forecasting, Norfolk, VA, Amer. Meteor. Soc., 547-550.

Lynch, D., K. Smith, B. Blanton, R. Luettich Jr., and F. Werner, 2004: Forecasting the coastal ocean: Resolution, tide, and operational data in the South Atlantic Bight. J. Atmos. Oceanic Technol., 21, 1074-1085.

Mattocks, C., and C. Forbes, 2008: A real-time, event-triggered storm surge forecasting system for the state of North Carolina. Ocean Modell., 25, 95-119, doi:10.1016/j.ocemod.2008.06.008.

McGee, B. D., B. B. Goree, R. W. Tollett, and R. R. Mason Jr., cited 2008: Monitoring inland storm surge and flooding from Hurricane Gustav in Louisiana, September 2008. U.S. Geological Survey Open-File Rep. 2008-1373. [Available online at http://pubs.usgs.gov/of/2008/1373/.]

Moyer, A. C., J. L. Evans, and M. Powell, 2007: Comparison of observed gale radius statistics. Meteor. Atmos. Phys., 97, 41-55.

National Hurricane Center, 2008: Official NHC 5-year average forecast errors (2005-2009) all tropical cyclones. [Available online at http://www.nhc.noaa.gov/verification/pdfs/OFCL 5-yr_averages.pdf.]

NOAA, cited 2009a: Sea level stations. [Available online at http:// www.tidesandcurrents.noaa.gov/sltrends/sltrends.html.]

_ 2009b: Sea level variations of the United States 1854-2006. NOAA Tech. Rep. NOS CO-OPS 053, 194 pp.

Powell, M. D., S. H. Houston, L. R. Amat, and N. Morisseau-Leroy, 1998: The HRD real-time hurricane wind analysis system. J. Wind Eng. Indust. Aerodyn., 77/78, 53-64.

Resio, D. T., and J. J. Westerink, 2008: Modeling the physics of hurricane storm surges. Phys. Today, 61 (9), 33-38.

Rogers, R., cited 2009: NOAA hurricane research and plans for 2010 field campaign. NASA Hurricane Science Research Program Science Team Meeting, The Florida State University, Tallahassee FL. [Available online at http://hsrp.nsstc.nasa.gov/ documents/rogers.pdf.]

Shields, R., 2003: NGS geodetic toolkit. Part 3: LVL_DH, and tidal and orthometric elevations. Prof. Surveyor Mag., 23 (7). [Available online at http://www.profsurv.com/magazine/pdf/ archives/psm_200307_geodetic_toolkit_p3.pdf.]

Tanaka, S., S. Bunya, J. J. Westerink, C. Dawson, and R. A. Luettich Jr., 2010: Scalability of an unstructured grid continuous Galerkin based hurricane storm surge model. J. Sci. Comput., doi:10.1007/s10915-010-9402-1, in press.

USACE, cited 2009: Louisiana Coastal Protection and Restoration (LACPR) final technical report. U.S. Army Corps of Engineers. [Available online at http://lacpr.usace.army.mil/default. aspx? $\mathrm{p}=$ LACPR_Final_Technical_Report.]

Vickery, P. J., P. F. Skerlj, and L. A. Twisdale, 2000: Simulation of hurricane risk in the U.S. using empirical track model. J. Struct. Eng., 126, 1222-1237.

Westerink, J. J., and Coauthors, 2008: A basin to channel scale unstructured grid hurricane storm surge model as implemented for southern Louisiana. Mon. Wea. Rev., 136, 833-864.

World Meteorological Organization, 2008: WMO statement on status of the global climate in 2008. WMO Rep. No.-1039, 13 pp. [Available online at http://www.wmo.ch/pages/publications/ showcase/documents/WMO1039_EN_web.pdf.] 